\title{
Phytoplankton flora of two rivers in Southeast Brazil - Paraibuna and Pomba Rivers, Minas Gerais
}

\author{
MARIA CAROLINA S. SOARES ${ }^{1,2}$, MARIA DA GRAÇA SOPHIA ${ }^{1}$ and \\ VERA L. DE M. HUSZAR ${ }^{1}$
}

(received: May 5, 2005; accepted: July 19, 2007)

\begin{abstract}
Phytoplankton flora of two rivers in Southeast Brazil - Paraibuna and Pomba Rivers, Minas Gerais). This work is a survey of the phytoplankton communities of the Paraibuna and Pomba Rivers. It aims is to contribute to the existing albeit scarce knowledge of the phytoplankton of Minas Gerais and of lotic phytoplankton in general. The results are based on 32 samples collected from Paraibuna and Pomba Rivers, in Minas Gerais State, during the dry (July and August, 2001) and rainy seasons (February 2002). Forty-eight taxa were identified, 20 from Paraibuna River and 28 from Pomba River, thirty-eight of which are new records for Minas Gerais State. The phytoplankton community of Paraibuna River was strongly influenced by a reservoir close to its source, thus the occurrence of lentic species of cyanobacteria and desmids. However, the phytoplankton community of Pomba River was typical of lotic environments, with great number of diatoms and desmids.
\end{abstract}

Key words - potamoplankton, taxonomy, tropical rivers

RESUMO - (Flora fitoplanctônica de dois rios no Sudeste do Brasil - Rios Paraibuna e Pomba, Minas Gerais). É apresentada a composição fitoplanctônica dos Rios Paraibuna e Pomba, contribuindo para o escasso conhecimento do fitoplâncton de ambientes lóticos e também do Estado de Minas Gerais. Os resultados são baseados em 32 amostras coletadas nos Rios Paraibuna e Pomba, em Minas Gerais, durante a estação seca (agosto, julho/2001) e chuvosa (fevereiro/2002). Foram identificados 48 táxons, sendo 20 no Rio Paraibuna e 28 no Rio Pomba. Destes, 38 são primeira citação para o Estado de Minas Gerais. O fitoplâncton do Rio Paraibuna foi influenciado pela presença de um reservatório, favorecendo a ocorrência de cianobactérias de ambientes lênticos juntamente com desmídias. A composição do Rio Pomba foi tipicamente de ambientes lóticos, com maior número de diatomáceas e desmídias.

Palavras-chave - potamoplâncton, rios tropicais, taxonomia

\section{Introduction}

River phytoplankton has never received the same attention from phycologists or ecologists as phytoplankton from lakes (Reynolds \& Descy 1996). According to Reynolds et al. (1994), the occurrence of phytoplankton in rivers is highly influenced by turbulence and low light intensity, which produces high richness of diatoms and green algae in rivers worldwide. In tropical rivers, where the variability of species is greater than in temperate rivers, desmids is another important group of phytoplankton (Rojo et al. 1994).

Potamoplankton also attracts scarce attention in Brazil. Despite the extensive Brazilian hydrographic system, the number of studies on phytoplankton community structure in lotic systems is much smaller than in lentic ones. In Brazil, pioneer studies were carried out in the Amazonian region rivers, such as Negro River, Tapajós River and Madeira River (Dickie 1881, Förster 1963,

\footnotetext{
1. Universidade Federal do Rio de Janeiro, Museu Nacional, Horto Botânico, Laboratório de Ficologia, Quinta da Boa Vista, São Cristóvão, 20940-040 Rio de Janeiro, RJ, Brasil.

2._Corresponding author: mcarolsoares@gmail.com
}

1964, 1969, Scott et al. 1965, Thomasson 1971). Most of the taxonomic studies of river phytoplankton in Brazil are concentrated in the southern states. The diatom flora from rivers in Rio Grande do Sul State was described by Corte-Real \& Aguiar (1972), Martau et al. (1977), Torgan \& Aguiar (1978), Buselato \& Aguiar (1979), Laudares-Silva (1987), Lobo \& Torgan (1988), Callegaro et al. (1993) and Lobo et al. (1996). In Santa Catarina State by Rodrigues $(1982,1992)$ and Rodrigues \& Moreira Filho (1990). In Paraná State Bittencourt-Oliveira (2002) described the phytoplankton community of River Tibagi. In the same state Contin (1990), Ludwig \& Flôres (1995, 1997), Brassac et al. (1999), Brassac \& Ludwig (2003), Brassac \& Ludwig (2005) and Landucci \& Ludwig (2005) carried out a survey of diatoms of various rivers. In the Southeast, Bicudo et al. (1992) and Bicudo et al. (1993) studied phytoplankton and diatoms, respectively, in Paranapanema River in a region to be dammed by Rosana Hydroelectric Power Plant. Necchi Júnior \& Pascolato (1993), Necchi Júnior et al. (1994), Necchi Júnior \& Moreira (1995), Branco \& Necchi Júnior (1996, 1998), Branco et al. (1999) and Necchi Júnior et al. (2000) provided information of macroalgae distribution and composition in São Paulo State. The taxonomic studies in Minas Gerais 
State are scarce, even for lakes and reservoirs. Nordstedt (1870, 1877, 1878), Warming (1892), Wille (1884), Bicudo \& Ventrice (1968), Bicudo (1969), Sormus (1991, 1993, 1996) and Oliveira (2001) described desmids from different environments, while Eterovick \& Giani (1997) and Giani et al. (1999) surveyed the phytoplankton of the Pampulha Reservoir. Other taxonomic works include a study of the green algae from a pool located at the "Universidade Federal de Viçosa" (Lovo 1997), a work on diatoms from "Universidade Federal de Juiz de Fora" lake (Costa \& Torgan 1991) and another survey on diatoms from Salto River, in "Parque Nacional do Ibitipoca" (Canani 2005).

The objective of this work is to improve the scarce knowledge of lotic phytoplankton, especially for Minas Gerais State, describing the flora of the Paraibuna and Pomba Rivers.

\section{Material and methods}

The Paraibuna and Pomba Rivers are the main tributaries of Paraíba do Sul River in Minas Gerais (figure 1). The climate is moderate wet subtropical (Cwa, Köppen), with annual average precipitation from 1,200 to $1,600 \mathrm{~mm}$ and annual average temperature between $17.4{ }^{\circ} \mathrm{C}$ and $24.7{ }^{\circ} \mathrm{C}$. The Paraibuna River is $176 \mathrm{~km}$ in length, with a $6,859 \mathrm{~km}^{2}$ basin and flows into Paraíba do Sul River. Thirty-three kilometers away from the source, the river is dammed, to form the Chapéu D'Uvas Reservoir, with a surface area of $12 \mathrm{~km}^{2}$, volume of 146 million cubic meters and maximum depth of $41 \mathrm{~m}$. According to historical average values, the Paraibuna River flow is greatest in its lower stretches, where the gradient is steepest. The greatest flow rates occur during the months of January and February. The Pomba River runs for $265 \mathrm{~km}$ and flows into the Paraíba do Sul River. Its catchments area is $8,735 \mathrm{~km}^{2}$ and the historical average flow rate is $130 \mathrm{~m}^{3} \mathrm{~s}^{-1}$ (Torres 1992).

The study of phytoplankton community was based on 32 samples collected at nine and seven stations in Paraibuna and Pomba Rivers, respectively, during dry (July, August, 2001) and rainy seasons (February, 2002) (table 1). Samples were collected by filling bottles directly in the water and fixed in acetic Lugol's solution in $0.05 \%$ or with a $25 \mu \mathrm{m}$ mesh net and fixed with Transeau's solution. For diatoms study, slides were prepared according to Van Stoch (1970) using Naphrax. Samples were deposited at the Herbarium of the "Departamento de Botânica", "Museu Nacional", "Universidade Federal do Rio de Janeiro" (R).

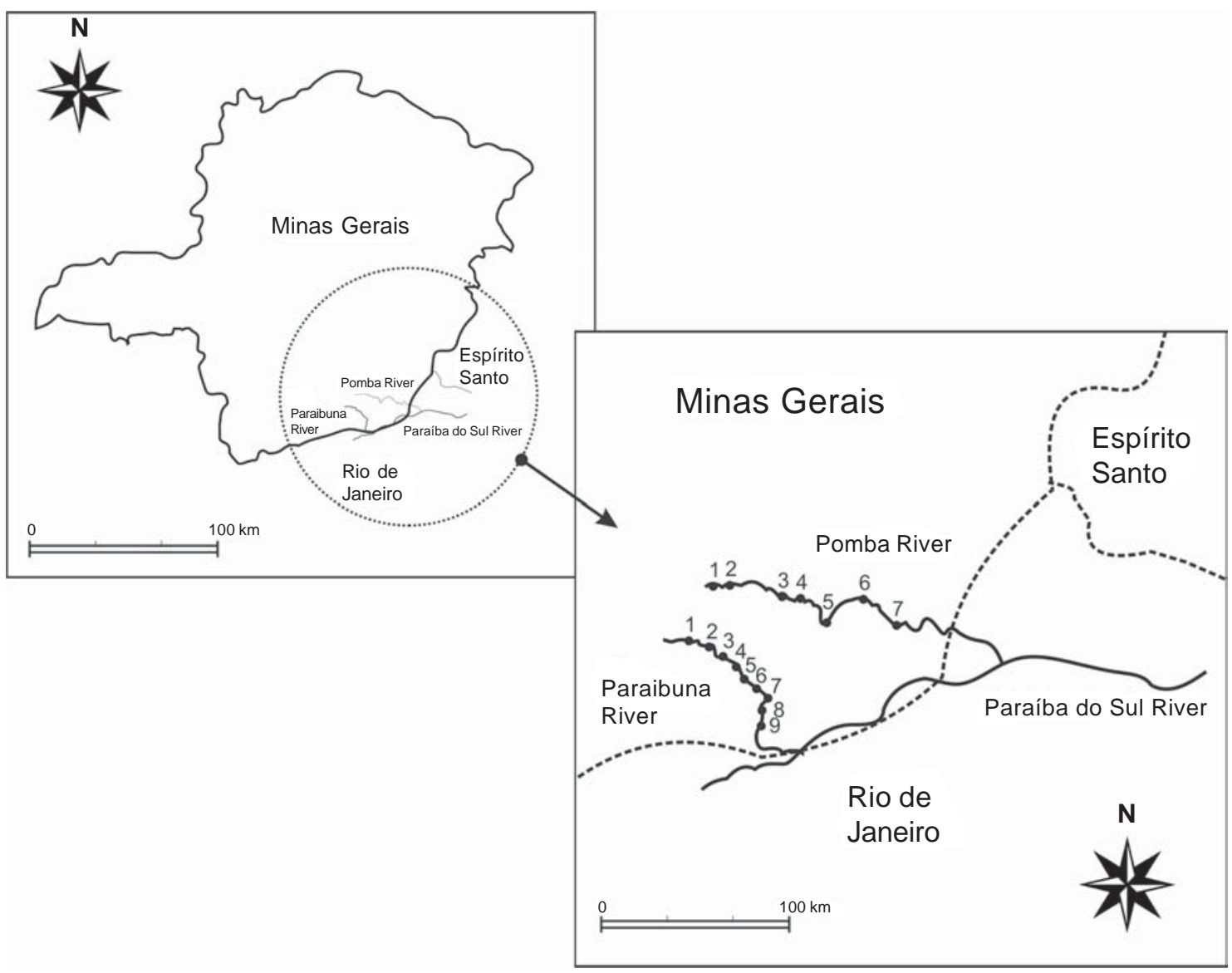

Figure 1. Map of Pomba and Paraibuna Rivers catchments showing the sample sites. 
Table 1. Geographic coordinates (GC) of sampling sites (SS) in Paraibuna and Pomba Rivers and its herbarium number (R).

\begin{tabular}{|c|c|c|c|c|c|}
\hline \multicolumn{3}{|c|}{ PARAIBUNA RIVER } & \multicolumn{3}{|c|}{ POMBA RIVER } \\
\hline GC & SS & Date/R & GC & SS & Date/R \\
\hline $\begin{array}{ll}21^{\circ} 30^{\prime} 14^{\prime \prime} & \mathrm{S} \\
43^{\circ} 38^{\prime} 27^{\prime \prime} & \mathrm{W}\end{array}$ & 1. Dores do Paraibuna & $\begin{array}{l}2-\mathrm{VII}-01 / 205584 \\
23-\mathrm{II}-02 / 205593\end{array}$ & $\begin{array}{l}21^{\circ} 16^{\prime} 05,9^{\prime \prime} \mathrm{S} \\
43^{\circ} 38^{\prime} 04,3^{\prime \prime} \mathrm{W}\end{array}$ & $\begin{array}{l}\text { 1. Santa Bárbara } \\
\text { do Tugúrio I }\end{array}$ & $\begin{array}{l}16-\mathrm{VIIII}-01 / 205567 \\
24-\mathrm{III}-02 / 205574\end{array}$ \\
\hline $\begin{array}{l}21^{\circ} 35^{\prime} 16,9^{\prime \prime} \mathrm{S} \\
43^{\circ} 33^{\prime} 20,9^{\prime \prime} \mathrm{W}\end{array}$ & $\begin{array}{l}\text { 2. Chapéu D'Uvas } \\
\text { Reservoir, Juiz de Fora }\end{array}$ & $\begin{array}{l}2-\mathrm{VII}-01 / 205585 \\
23-\mathrm{II}-02 / 205594\end{array}$ & $\begin{array}{l}21^{\circ} 14^{\prime} 58,2^{\prime \prime} \mathrm{S} \\
43^{\circ} 34^{\prime} 03,9^{\prime \prime} \mathrm{W}\end{array}$ & $\begin{array}{l}\text { 2. Santa Bárbara } \\
\text { do Tugúrio II }\end{array}$ & $\begin{array}{l}16-\mathrm{VIIII}-01 / 205568 \\
24-\mathrm{II}-02 / 205575\end{array}$ \\
\hline $\begin{array}{l}21^{\circ} 35^{\prime} 26,8^{\prime \prime} \mathrm{S} \\
43^{\circ} 30^{\prime} 36,4^{\prime \prime} \mathrm{W}\end{array}$ & $\begin{array}{l}\text { 3. Chapéu D'Uvas, } \\
\text { Juiz de Fora }\end{array}$ & $\begin{array}{l}2-\mathrm{VII}-01 / 205586 \\
23-\mathrm{II}-02 / 205595\end{array}$ & $\begin{array}{l}2^{\circ} 14^{\prime} 04,1^{\prime \prime}, \mathrm{S} \\
43^{\circ} 19^{\prime} 06,2^{\prime \prime} \mathrm{W}\end{array}$ & 3. Mercês & $\begin{array}{l}16-\mathrm{VIII}-01 / 205569 \\
24-\mathrm{II}-02 / 205576\end{array}$ \\
\hline $\begin{array}{l}21^{\circ} 38^{\prime} 44,3^{\prime \prime} \mathrm{S} \\
43^{\circ} 26^{\prime} 14,6^{\prime \prime} \mathrm{W}\end{array}$ & 4. Barreira, Juiz de Fora & $\begin{array}{l}2-\mathrm{VII}-01 / 205587 \\
23-\mathrm{II}-02 / 205596\end{array}$ & $\begin{array}{l}21^{\circ} 16^{\prime} 51,4^{\prime \prime} \mathrm{S} \\
43^{\circ} 10^{\prime} 33,4^{\prime \prime} \mathrm{W}\end{array}$ & 4. Rio Pomba & $\begin{array}{l}16-\mathrm{VIIII}-01 / 205570 \\
24-\mathrm{II}-02 / 205577\end{array}$ \\
\hline $\begin{array}{l}21^{\circ} 41^{\prime} 27,8^{\prime \prime} \mathrm{S} \\
43^{\circ} 25^{\prime} 38,4^{\prime \prime} \mathrm{W}\end{array}$ & $\begin{array}{l}\text { 5. Distrito Industrial, } \\
\text { Juiz de Fora }\end{array}$ & $\begin{array}{l}2-\mathrm{VII}-01 / 205588 \\
23-\mathrm{II}-02 / 205597\end{array}$ & $\begin{array}{l}21^{\circ} 18^{\prime} 54,4^{\prime \prime} \mathrm{S} \\
42^{\circ} 51^{\prime} 41,8^{\prime \prime} \mathrm{W}\end{array}$ & 5. Astolfo Dutra & $\begin{array}{l}16-\mathrm{VIIII}-01 / 205571 \\
24-\mathrm{III}-02 / 205578\end{array}$ \\
\hline $\begin{array}{l}21^{\circ} 43^{\prime} 54,2^{\prime \prime} \mathrm{S} \\
43^{\circ} 23^{\prime} 19,7^{\prime} \mathrm{W}\end{array}$ & $\begin{array}{l}\text { 6. Milho Branco, } \\
\text { Juiz de Fora }\end{array}$ & $\begin{array}{l}2-\mathrm{VII}-01 / 205589 \\
23-\mathrm{II}-02 / 205598\end{array}$ & $\begin{array}{l}21^{\circ} 23^{\prime} 32,1^{\prime \prime} \mathrm{S} \\
42^{\circ} 41^{\prime} 35,7^{\prime \prime} \mathrm{W}\end{array}$ & 6. Cataguases & $\begin{array}{l}16-\mathrm{VIII}-01 / 205572 \\
24-\mathrm{II}-02 / 205579\end{array}$ \\
\hline $\begin{array}{l}21^{\circ} 45^{\prime} 32,9^{\prime \prime} \mathrm{S} \\
43^{\circ} 20^{\prime} 31,1^{\prime \prime} \mathrm{W}\end{array}$ & 7. Halfeld, Juiz de Fora & $\begin{array}{l}2-\mathrm{VII}-01 / 205590 \\
23-\mathrm{II}-02 / 205599\end{array}$ & $\begin{array}{l}21^{\circ} 23^{\prime} 35,3^{\prime \prime} \mathrm{S} \\
42^{\circ} 29^{\prime} 25,0^{\prime \prime} \mathrm{W}\end{array}$ & 7. Laranjal & $\begin{array}{l}16-\mathrm{VIIII}-01 / 205573 \\
24-\mathrm{II}-02 / 205580\end{array}$ \\
\hline $\begin{array}{l}21^{\circ} 47^{\prime} 15,1^{\prime \prime} \mathrm{S} \\
43^{\circ} 18^{\prime} 14,4^{\prime \prime} \mathrm{W}\end{array}$ & $\begin{array}{l}\text { 8. Marmelos I, } \\
\text { Juiz de Fora }\end{array}$ & $\begin{array}{l}2-\mathrm{VII}-01 / 205591 \\
23-\mathrm{II}-02 / 205600\end{array}$ & $\begin{array}{l}21^{\circ} 27^{\prime} 27,2^{\prime \prime} \mathrm{S} \\
42^{\circ} 21^{\prime} 01,0^{\prime \prime} \mathrm{W}\end{array}$ & & \\
\hline $\begin{array}{l}21^{\circ} 54^{\prime} 53,3^{\prime \prime} \mathrm{S} \\
43^{\circ} 20^{\prime} 41,6^{\prime \prime} \mathrm{W}\end{array}$ & 9. Cotegipe & $\begin{array}{l}2-\mathrm{VII}-01 / 205592 \\
23-\mathrm{II}-02 / 205601\end{array}$ & & & \\
\hline
\end{tabular}

The taxonomic classification for division and classes levels followed Van den Hoek et al. (1995), with exception of Bacillariophyta, which followed Round et al. (1990). The infraclasses hierarchy followed Anagnostidis \& Komárek (1988) and Komárek \& Anagnostidis $(1989,1999)$ for Cyanophyceae; Round et al. (1990) for Coscinodiscophyceae, Fragilariophyceae and Bacillariophyceae, Ettl (1978) for Xanthophyceae; Klaveness (1985) for Cryptophyceae; Tell \& Conforti (1986) and Zákrys (1986) for Euglenophyceae; Ettl (1983) and Komárek \& Fott (1983) for Chlorophyceae; and Ruzicka (1977, 1981) for Zygnematophyceae.

For the geographic distribution of species in Minas Gerais State, only descriptions with illustrations were considered.

\section{Results and discussion}

The 48 specific and infraspecific taxa identified were representative of eight taxonomic classes: Cyanophyceae (cyanobacteria), Coscinodiscophyceae, Fragilariophyceae, Bacillariophyceae (grouped as diatoms), Xanthophyceae, Euglenophyceae, Chlorophyceae (green algae) and Zygnematophyceae (desmids). Twenty of them were from the Paraibuna River and twenty-eight from the Pomba River. Cyanobacteria and desmids were the most important groups in Paraibuna River while diatoms and desmids were the main groups in Pomba River (figure 2). Twenty-nine of the total specific and infraspecific taxa were identified to species level and 19 to infraspecific level. Thirty-eight were recorded for the first time to the Minas Gerais State. In general, the most important groups in terms of the number of species were cyanobacteria, diatoms and desmids (figure 2). Thirty-two taxa were exclusively from the dry period while six taxa were reported only in the rainy period and 10 were common during both periods (table 2). Flooding seems to be the most important event contributing to the decrease in taxa number during rainy period, especially in green algae and desmids. During this period some samples had no algae, especially those located downstream, where flow and turbidity were high. Chapéu D'Uvas Reservoir, near to the Paraibuna River source, influenced the phytoplankton composition, favoring the occurrence of lentic species of cyanobacteria (seven taxa) and desmids (seven taxa). From the 14 taxa registered in the reservoir, eight were exclusively found in this system, but others were also found downstream, especially in the dry period. Cylindrospermopsis raciborskii and Cosmarium sphagnicolum were found in the reservoir and were also distributed along the river. The higher number of 
A
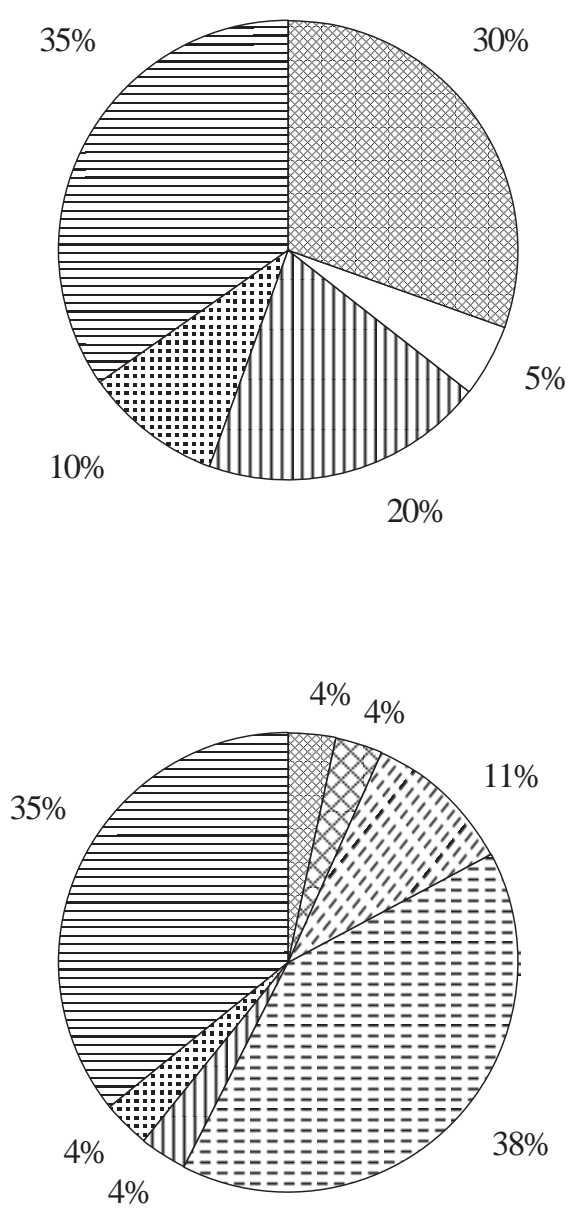

Figure 2: Phytoplankton composition in Paraibuna (A) and Pomba (B) rivers.

$$
\begin{aligned}
& \text { = Cyanophyceae, } \otimes=\text { Coscinodiscophyceae, } \\
& \text { [3ragilariophyceae, } \quad E=\text { Bacillariophyceae, } \\
& \square \text { = Xanthophyceae, } \quad \square=\text { Euglenophyceae, }
\end{aligned}
$$

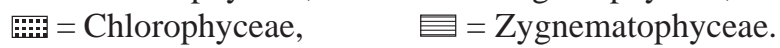

taxa in Paraibuna River was found in the reservoir and at the river's middle reaches (table 2). Pomba River composition was typical of lotic environment, with the greater number of taxa belonging to diatoms (16 taxa) and desmids (10 taxa) (figure 2). In the Pomba River, the highest number of species was found at the middle reaches (3-5), which provided $70 \%$ of total taxa from this river. In general each taxon was recorded only in few sites, with the exception of Navicula cryptocephala, which was found from station 3 to station 7 (table 2).

The 48 specific and infraspecific taxa recorded during this study are the follow:

\section{CYANOPHYCEAE}

\section{CHROOCOCCALES}

\section{SYNECHOCOCCACEAE}

Aphanothece stagnina (Spreng.) A. Braun in Rabernhorst, Decades 57-58:1572. 1863.

Figure 3

Colonies spherical or irregularly elongate, $15-50$ x 20-40 $\mu \mathrm{m}$; mucilage colourless; cells oblong, 5-6 x 3-4 $\mu$ m, with pale blue green, granular content.

Specimens examined: BRAZIL: MinAs GeraIs: Pomba River, 16-VIII-2001, M.C.S. Soares s.n. (R205567). Distribution in Minas Gerais State: new record.

Cyanogranis ferruginea (Wawrik) Hindák, Algolog. Stud. 32:244. 1982.

Figure 39

Colonies spherical or irregular, 8-15 $\mu$ m diameter; cells sometimes enveloped by ferric, blackish precipitates, which are occasionally aggregated on the periphery of cell groups; mucilage very fine; cells spherical to slightly oval, 1.0-1.5 x 0.6-1.0 $\mu \mathrm{m}$, with pale blue green content. Specimens examined: BRAZIL: MINAS GERAIS: Paraibuna River, 2-VII-2001, M.C.S. Soares s.n. (R205585, R205586, R205587, R205588); 23-II-2002, M.C.S. Soares s.n. (R205594).

Distribution in Minas Gerais State: new record.

\section{CHROOCOCCACEAE}

Chroococcus dispersus (Keissl.) Lemmerm., Ark. Bot. 2:102. 1904.

Figure 4

Colonies spherical or irregular, 8-10 $\mu$ m diameter; mucilage clearly delimitated; cells spherical or hemispherical, 3-4 $\mu \mathrm{m}$ diameter, content homogeneous.

Specimens examined: BRAZIL: Minas Gerais: Paraibuna River, 2-VII-2001, M.C.S. Soares s.n. (R205584).

Distribution in Minas Gerais State: new record.

\section{NOSTOCALES}

\section{NOSTOCACEAE}

Cylindrospermopsis raciborskii (Wolosz.) Seenaya \& Subba Raju, in Desikachary, Taxonomy and Biology of Blue-green Algae 52:57. 1972.

Figures 5-6

Trichomes solitary, 24-240 $\mu \mathrm{m}$ long, straight or slightly curved, constricted; cells cylindrical, 5-9 x 1-2 $\mu \mathrm{m}$, with aerotopes; heterocytes conical, terminal, $4-8 \times 1-2 \mu \mathrm{m}$; akinetes cylindrical, distant from the heterocyte by few cells, 8-9 × 2-3 $\mu \mathrm{m}$. 

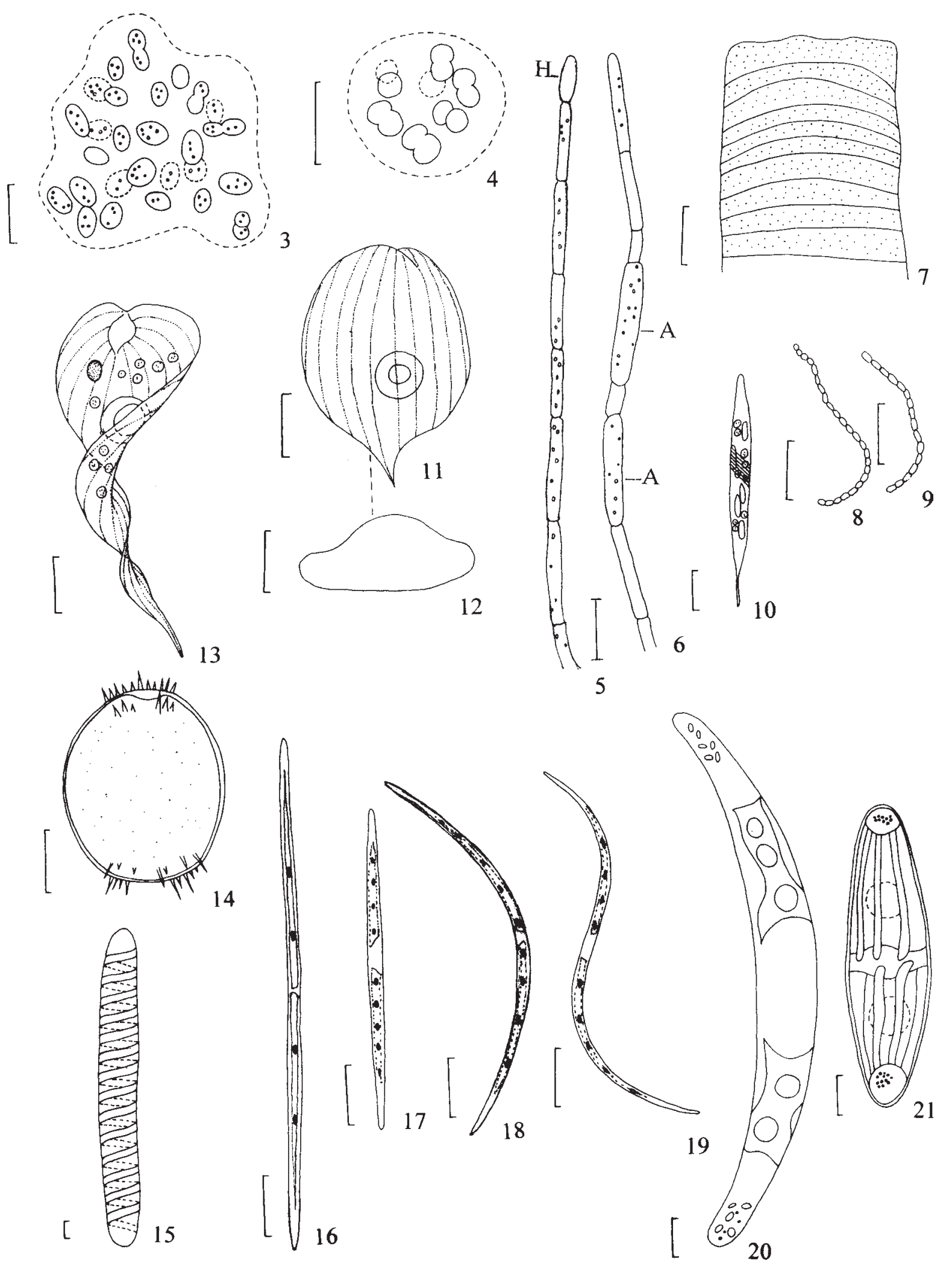

Figures 3-21. Cyanophyceae, Euglenophyceae and Zygnematophyceae from Paraibuna and Pomba rivers. 3. Aphanothece stagnina. 4. Chroococcus disperses. 5-6. Cylindrospermopsis raciborskii (A) akinete $(\mathrm{H})$ heterocyte. 7. Oscillatoria princes. 8-9. Romeria. 10. Euglena acus var. acus. 11-12. Phacus denisii. 11. Frontal view. 12. Vertical view. 13. P. longicauda var. tortus. 14. Trachelomonas armata var. armata. 15. Spirotaenia condensata. 16. Closterium acutum var. acutum. 17. C. acutum var. linea. 18-19. C. acutum var. variabile, morphological expressions. 20. C. leibleinii var. leibleinii. 21. C. navicula var. navicula. Bars $=10 \mu \mathrm{m}$. 


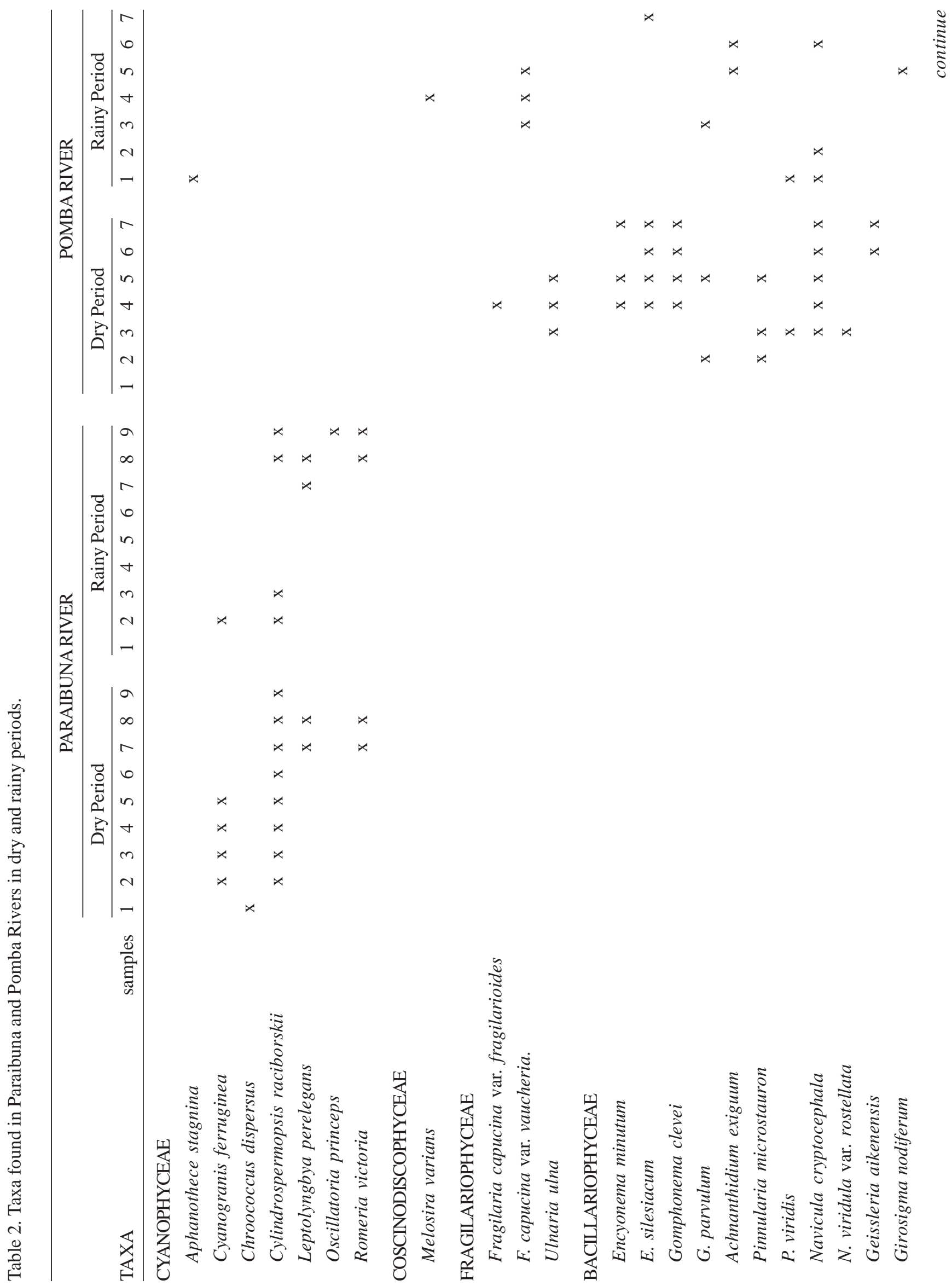




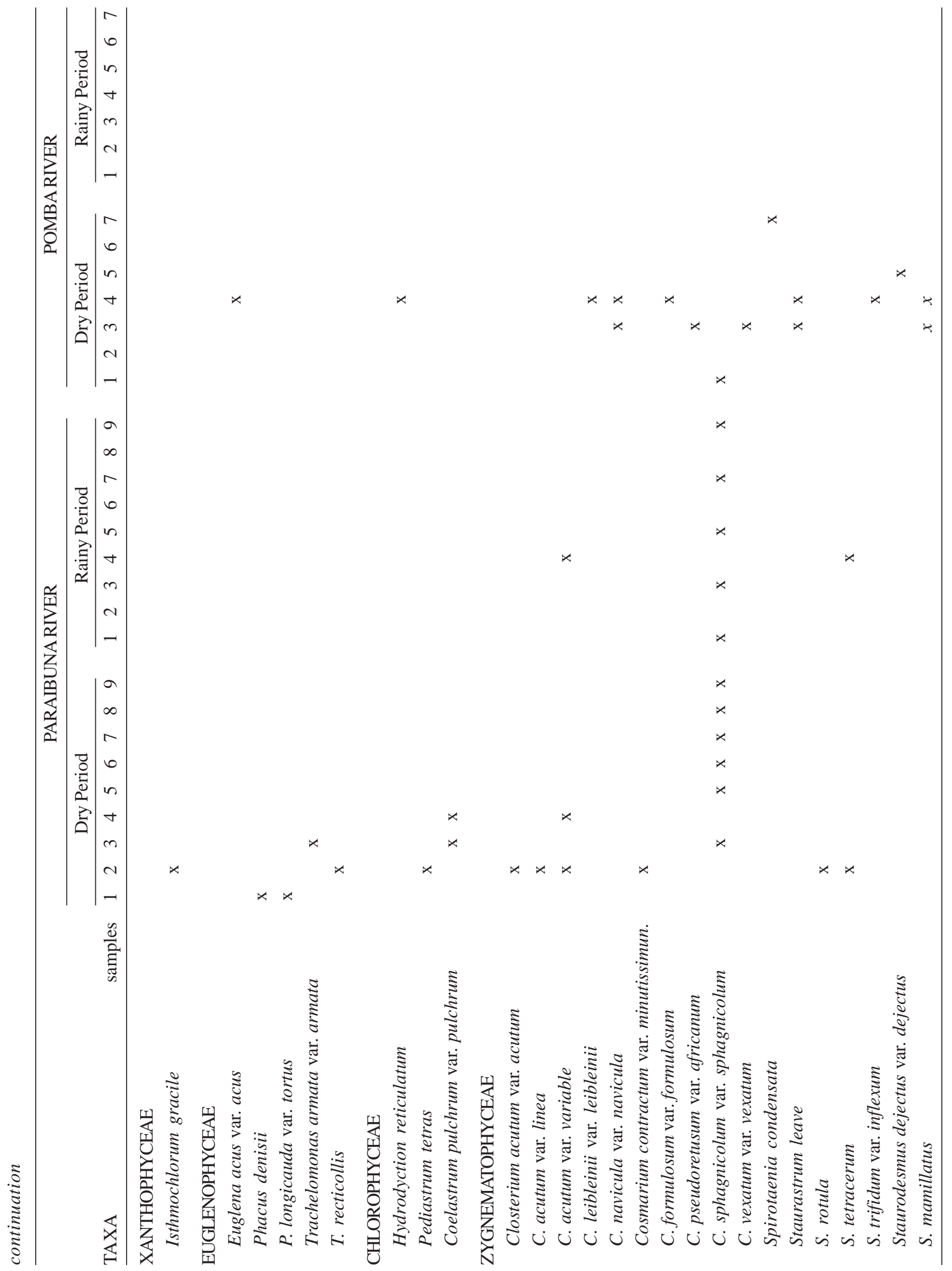


Specimens examined: BRAZIL: MinAS GERAIS: Paraibuna River, 2-VII-2001, M.C.S. Soares s.n. (R205585, R205586, R205587, R205588, R205589, R205590, R205591, R205592); 23-II-2002, M.C.S. Soares s.n. (R205594, R205595, R205600, R205601).

Distribution in Minas Gerais State: new record.

OSCILLATORIALES

\section{PSEUDANABAENACEAE}

Leptolyngbya perelegans (Lemmerm.) Anagn. \& Komárek, Algolog. Stud. 53:392. 1988.

Figure 40

Filaments solitary, 1.0-1.2 $\mu \mathrm{m}$ wide, straight, with thin colourless sheaths; trichomes not constricted; cells content blue green, homogeneous; cross-walls with two granules on either side; end-cell rounded, without thickened outer membrane.

Specimens examined: BRAZIL: MINAS GERAIS: Paraibuna River, 2-VII-2001, M.C.S. Soares s.n. (R205590, R205591); 23-II-2002, M.C.S. Soares s.n. (R205598, R205599). Distribution in Minas Gerais State: new record.

Oscillatoria princeps Vaucher ex Gomont, Ann. Sci. Nat. Bot. 16:206. 1892.

Figure 7

Trichomes straight or slightly curved, not attenuated, not constricted 35-37 $\mu \mathrm{m}$ diameter; cell 2-4 $\mu \mathrm{m}$, contents pale blue green, granulated; apical cells capitated, with thickened outer membrane.

Specimens examined: BRAZIL: MINAS GERAIS: Paraibuna River, 23-II-2002, M.C.S. Soares s.n. (R205592).

Distribution in Minas Gerais State: new record.

Romeria victoria Komárek \& Cronberg., Nova Hedwigia 73(1-2):141. 2001.

Figure 8-9

Trichomes solitary, slightly arcuated or irregularly waved, constricted; cells rod-shaped, 0.8-1.6 $\mu \mathrm{m}$ wide, contents pale blue green.

Specimens examined: BRAZIL: MinAS GERAIS: Paraibuna River, 2-VII-2001, M.C.S. Soares s.n. (R205590); 23-II2002, M.C.S. Soares s.n. (R205600, R205601).

Distribution in Minas Gerais State: new record.

\section{COSCINODISCOPHYCEAE}

\section{MELOSIRALES}

\section{MELOSIRACEAE}

Melosira varians C. Agardh, Bot. Zeitung (Berlin) p.628.1827.

Figure 41

Valves cylindrical in pleural view, on filamentous straight chains; lacking sulco. Diameter 15-30 $\mu \mathrm{m}$, length 20-30 $\mu \mathrm{m}$ length.
Specimens examined: BRAZIL: Minas GeRAIs: Pomba River, 24-II-2002, M.C.S. Soares s.n. (R205577).

Distribution in Minas Gerais State: new record.

\section{FRAGILARIOPHYCEAE}

\section{FRAGILARIALES}

\section{FRAGILARIACEAE}

Fragilaria capucina Desm. var. fragilarioides (Grunow) T. Ludwig \& Flôres, Hoehnea 24(1):55. 1997.

Figure 42

Valves linear-lanceolate; apices capitated to sub-capitated; axial area narrow; central area rectangular, bilaterally intumesced; parallel striae. Apical axis: 82-86 $\mu \mathrm{m}$; transapical axis: $8-12 \mu \mathrm{m}$; $5-6$ striae in $10 \mu \mathrm{m}$.

Specimens examined: BRAZIL: Minas GERAIS: Pomba River, 16-VIII-2001, M.C.S. Soares s.n. (R205570). Distribution in Minas Gerais State: new record.

Fragilaria capucina Desm. var. vaucheriae (Kütz.) Lange-Bert., Hedwigia 33:747. 1980.

Figure 43

Valves lanceolate to linear-lanceolate; apices sub-capitated to rostrate; axial area lanceolate to linear; central area rectangular; parallel striae. Apical axis: $13-15 \mu \mathrm{m}$; transapical axis: $2-3 \mu \mathrm{m}$; $13-15$ striae in $10 \mu \mathrm{m}$.

Specimens examined: BRAZIL: Minas GeraIs: Pomba River, 24-II-2002, M.C.S. Soares s.n. (R205576, R205577, R205578).

Distribution in Minas Gerais State: new record.

Ulnaria ulna (Nitzsch) Compère in Jahn et al., Studies on diatoms 97. 2001.

Figure 44

Valves linear to linear-lanceolate, without median constriction; apices rostrate to subcapitate; axial area linear; central area rectangular; parallel striae. Apical axis: 82-90 $\mu \mathrm{m}$; transapical axis: 6-7 $\mu \mathrm{m}$; 10-11 striae in $10 \mu \mathrm{m}$.

Specimens examined: BRAZIL: MinAs GeraIs: Pomba River, 16-VIII-2001, M.C.S. Soares s.n. (R205569, R205570, R205571).

Distribution in Minas Gerais State: new record.

\section{BACILLARIOPHYCEAE \\ CYMBELLALES \\ CYMBELLACEAE}

Encyonema minutum (Hilse) D.G. Mann in Round et al., Diatoms 667. 1990.

Figure 45

Valves dorsiventral and symmetrical to the transapical axis, dorsal margin arched, ventral margin straight or slightly biarcuate; apices rounded to rostrate; raphe 
more-or-less straight with central endings deflected dorsally and apical ends deflected ventrally. Apical axis: 14-17 $\mu \mathrm{m}$; transapical axis: $4-6 \mu \mathrm{m}$; 13 striae in $10 \mu \mathrm{m}$. Specimens examined: BRAZIL: Minas Gerais: Pomba River, 16-VIII-2001, M.C.S. Soares s.n. (R205570, R205571, R205573).

Distribution in Minas Gerais State: new record.

Encyonema silesiacum (Bleisch) Mann in Round et al., Diatoms 667. 1990.

Figure 46

Valves dorsiventral and symmetrical to the transapical axis, dorsal margin arched, ventral margin straight or slighty biarcuate, slightly enlarged on median region; apices rounded to rostrate; raphe more-or-less straight with central endings deflected dorsally and apical ends deflected ventrally. Apical axis: 25-38 $\mu \mathrm{m}$; transapical axis: $9-10 \mu \mathrm{m}$; $10-15$ striae in $10 \mu \mathrm{m}$.

Specimens examined: BRAZIL: Minas Gerais: Pomba River, 16-VIII-2001, M.C.S. Soares s.n. (R205570, R205571, R205572, R205573); 24-II-2002, M.C.S. Soares s.n. (R205580).

Distribution in Minas Gerais State: Juiz de Fora (Costa \& Torgan 1991, as Cymbella sylesiaca).

\section{GOMPHONEMATACEAE}

Gomphonema clevei Fricke, Atlas des Diatomaceenkundi 249-256. 1902.

Figure 47

Valves slightly asymmetrical to transapical axis (heteropolar), symmetrical to apical axis, lanceolate in outline; apices rounded; a single stigma is present on one side of the central area. Apical axis: 43-45 $\mu \mathrm{m}$; transapical axis: $8-9 \mu \mathrm{m} ; 16$ striae in $10 \mu \mathrm{m}$.

Specimens examined: BRAZIL: Minas Gerais: Pomba River, 16-VIII-2001, M.C.S. Soares s.n. (R205570, R205571, R205572, R205573).

Distribution in Minas Gerais State: new record.

Gomphonema parvulum (Kütz.) Kütz., Sp. Alg. 65.1849. Figure 48

Valves slightly asymmetrical to transapical axis (heteropolar), symmetrical to apical axis, appear lanceolate in outline, wedge-shaped in girdle view with pseudosepta visible; apices narrowly rounded to narrowly sub-rostrate; raphe often slightly sinuous; striae are coarse and punctate. Apical axis: 17-27 $\mu \mathrm{m}$; transapical axis: 4-7 $\mu \mathrm{m}$; 10-11 striae in $10 \mu \mathrm{m}$. Specimens examined: BRAZIL: Minas GeraIs: Pomba River, 16-VIII-2001, M.C.S. Soares s.n. (R205568, R205571); 24-II-2002, M.C.S. Soares s.n. (R205576). Distribution in Minas Gerais State: Juiz de Fora (Costa \& Torgan 1991).

\section{ACHNANTHALES}

ACHNANTHIDIACEAE

Achnanthidium exiguum (Grunow) Czarn., Proc. Int. Diatom Symp.11:157. 1994.

Figure 49

Valves linear, apices capitate-rostrate, rafe only in one valve. Apical axis: $12-14 \mu \mathrm{m}$; transapical axis: $4-5 \mu \mathrm{m} ; 16$ striae in $10 \mu \mathrm{m}$.

Specimens examined: BRAZIL: Minas Gerais: Pomba River, 24-II-2002, M.C.S. Soares s.n. (R205578, 205579). Distribution in Minas Gerais State: new record.

\section{NAVICULALES}

\section{PINNULARIACEAE}

Pinnularia microstauron (Ehrenb.) Cleve, Acta Soc. Fauna Fl. Fenn. 8(2):28. 1891.

Figure 50

Valves linear-lanceolate, apices subcapitate-rounded; axial area lanceolate; central area transverse; rafe linear reflected to the sides; transapical striae radiate in central area and convergent in the extremes. Apical axis: 35$60 \mu \mathrm{m}$; transapical axis: $8-13 \mu \mathrm{m}$; 12 striae in $10 \mu \mathrm{m}$. Specimens examined: BRAZIL: Minas GERAIS: Pomba River, 16-VIII-2001, M.C.S. Soares s.n. (R205568, R205569, R205571).

Distribution in Minas Gerais State: new record.

Pinnularia viridis (Nitzsch) Ehrenb., Ber. Bekanntm. Verh. Königl. Preuss. Akad. Wissensch. 139-144. 1841. Figure 51

Valves linear with rounded apices; apices convergent; axial area narrow near poles, widening gradually to the round or elliptical central area; striae transverse or slightly radiate at centre. Apical axis: 61-64 $\mu \mathrm{m}$; transapical axis: 9-12 $\mu \mathrm{m}$; 9-11 striae in $10 \mu \mathrm{m}$.

Specimens examined: BRAZIL: MinAs GeraIs: Pomba River, 16-VIII-2001, M.C.S. Soares s.n. (R205568); 24-II-2002, M.C.S. Soares s.n. (R205574).

Distribution in Minas Gerais State: Juiz de Fora (Costa \& Torgan 1991).

\section{NAVICULACEAE}

Navicula cryptocephala Kütz., Die kieselsichaligen Bacillarien oder Diatomeen 152, 1844.

Figure 52

Valves narrowly lanceolate; apices slightly sub-capitate; striae fine and radiate throughout the valves, transverse or slightly convergent at the apices; raphe lies in slightly thickened rib, slightly broader at centre but not markedly asymmetrical. Apical axis: $23-29 \mu \mathrm{m}$; transapical axis: $5-7 \mu \mathrm{m} ; 14$ striae in $10 \mu \mathrm{m}$. 

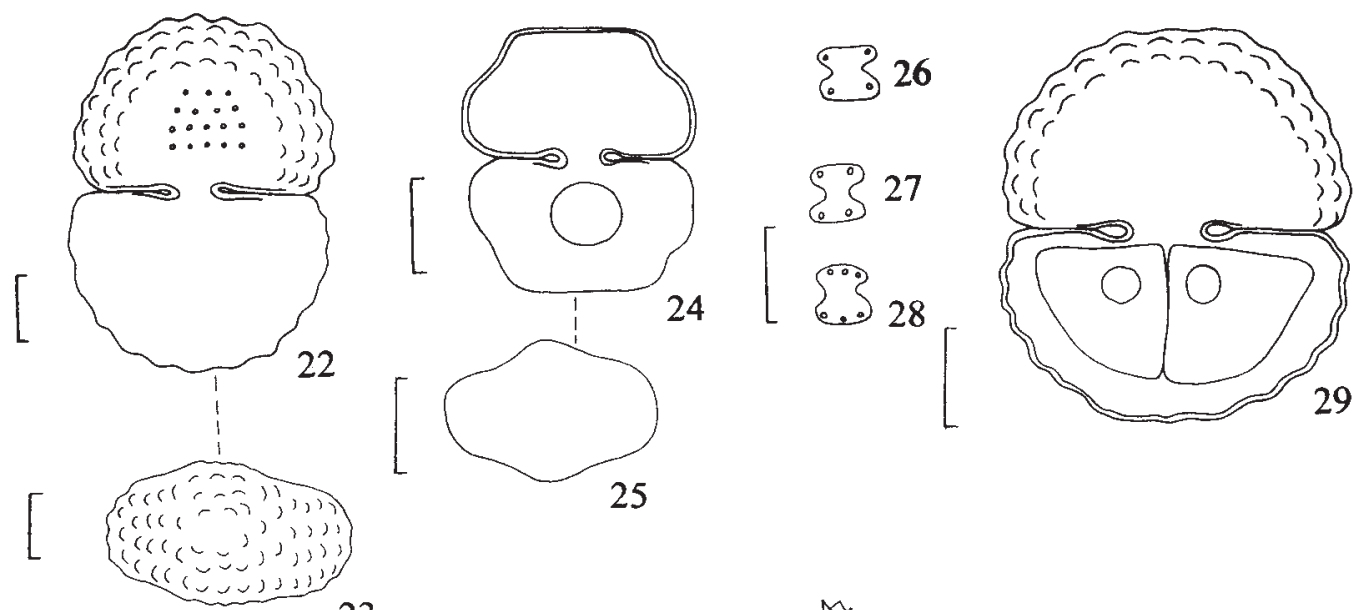

23
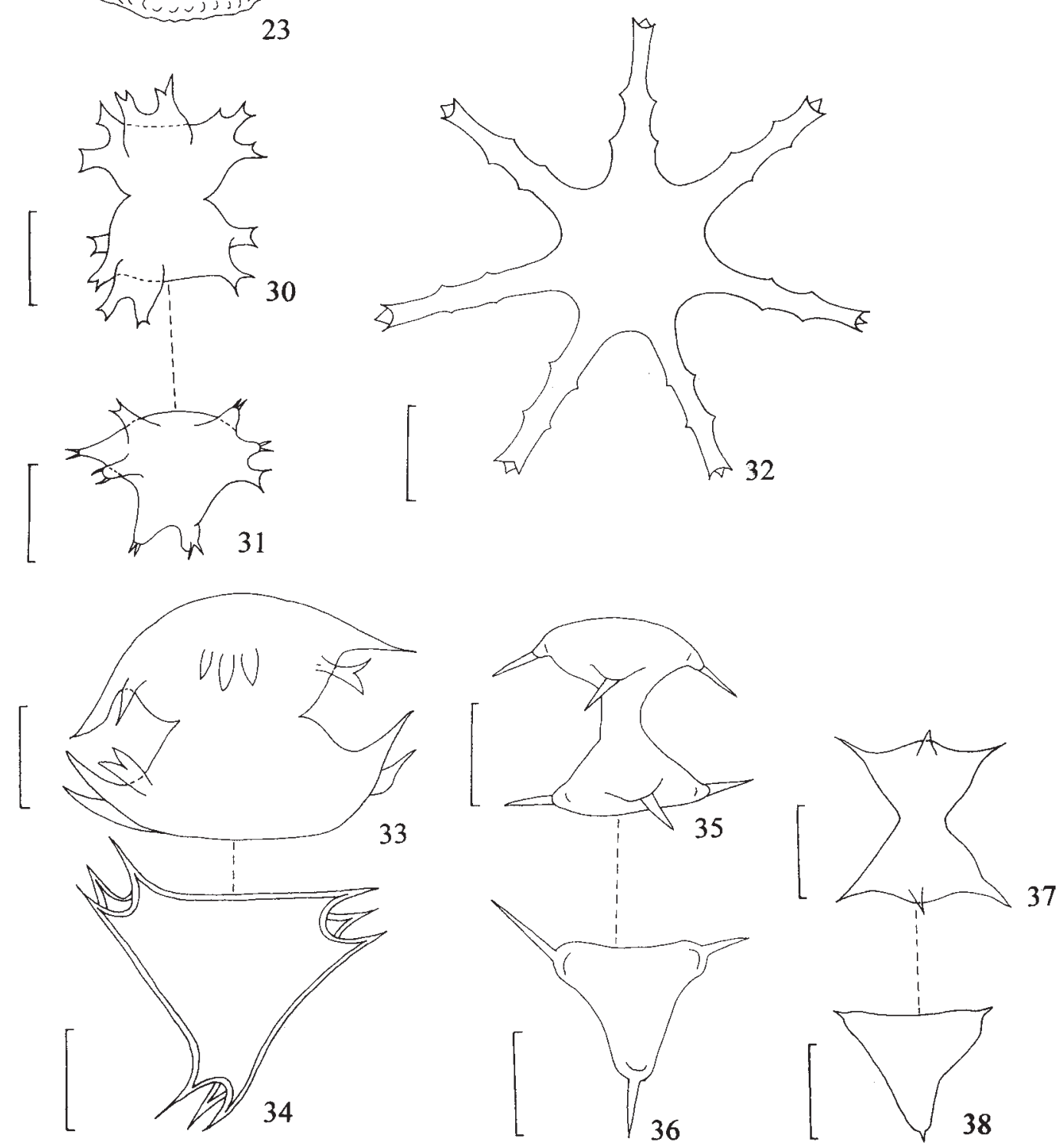

Figure 22-38. Zygnematophyceae from Paraibuna and Pomba rivers. 22-23. Cosmarium formulosum var. formulosum. 22. Frontal view. 23. Vertical view. 24-25. C. pseudoretusum var. africanum. 24. Frontal view. 25. Vertical view. 26-28. C. sphagnicolum var. sphagnicolum, morphological expressions. 29. C. vexatum var. vexatum. 30-31. Staurastrum leave. 30. Frontal view. 31 . Vertical view. 32. S. rotula, vertical view. 33-34. S. trifidum var. inflexum. 33. Frontal view. 34. Vertical view. 35-36. Staurodesmus dejectus var. dejectus. 35. Frontal view. 36. Vertical view. 37-38. S. mamillatus. 37. Frontal view. 38. Vertical view. Bars $=10 \mu \mathrm{m}$. 
Specimens examined: BRAZIL: Minas Gerais: Pomba River, 16-VIII-2001, M.C.S. Soares s.n. (R205569, R205570, R205571, R205572, R205573, R205574, R205575); 24-II-2002, M.C.S. Soares s.n. (R205579). Distribution in Minas Gerais State: Juiz de Fora (Costa \& Torgan 1991).

Navicula viridula (Kütz.) Ehrenb. var. rostellata (Kütz.) Cleve, Avenska VetenskAkad. Handdl. 27(3):15. 1895. Figure 53

Valves lanceolate; apices subrostrate; striae clearly lineate, radiate over most of the valve, but convergent at the poles; raphe fissures hooked over the apices, slightly expanded and deflected to one side at the centre. Apical axis: 70$89 \mu \mathrm{m}$; transapical axis: $10-15 \mu \mathrm{m}$; $10-11$ striae in $10 \mu \mathrm{m}$. Specimens examined: BRAZIL: Minas Gerais: Pomba River, 16-VIII-2001, M.C.S. Soares s.n. (R205569). Distribution in Minas Gerais State: new record.

Geissleria aikenensis (Patrick) Torgan \& Oliveira, Proc. Int. Diatom Symp. 16:115. 2001.

Figure 54

Valves linear to linear-elliptic; apices rostrate; axial area narrow, linear; central area transapically expanded; striae moderately radiate. Apical axis: $21 \mu \mathrm{m}$; transapical axis: $7 \mu \mathrm{m} ; 13-15$ striae in $10 \mu \mathrm{m}$.

Specimens examined: BRAZIL: Minas Gerais: Pomba River, 16-VIII-2001, M.C.S. Soares s.n. (R205572, 205573).

Distribution in Minas Gerais State: new record.

\section{PLEUROSIGMATACEAE}

Gyrosigma nodiferum (Grunow) Reimer, Diat. United States 320. 1966.

Figure 55

Valves slightly sigmoid, linear; apices attenuated, rounded; axial area narrow; central area oblique; raphe slightly sigmoid, strongly inclined and rounded; striae longitudinal. Apical axis: $65-70 \mu \mathrm{m}$; transapical axis: $12 \mu \mathrm{m} ; 20$ striae in $10 \mu \mathrm{m}$. Specimens examined: BRAZIL: MinAs GERAIS: Pomba River, 24-II-2002, M.C.S. Soares s.n. (R205578).

Distribution in Minas Gerais State: new record.

\section{XANTHOPHYCEAE}

\section{MISCHOCOCCALES}

\section{PLEUROCHLORIDACEAE}

Isthmochloron gracile (Reinsch) Skuja, Nova Acta Regia Soc. Sci. Upsal, ser. 4, 14(5):173. 1949.

Figure 56

Cells solitary, with 4 angles, each angle with 1 bifurcated process ending in spines, 31 x $38 \mu \mathrm{m}$, several discoidal chloroplasts.
Specimens examined: BRAZIL: Minas GeRAIS: Paraibuna River, 2-VII-2001, M.C.S. Soares s.n. (R205585).

Distribution in Minas Gerais State: new record.

\section{EUGLENOPHYCEAE}

\section{EUGLENALES}

\section{EUGLENACEAE}

Euglena acus Ehrenb. var. acus, Infus. 112. 1838. Figure 10

Cells elongate, fusiform, 77-95 × $6 \mu \mathrm{m}$, posterior end gradually attenuated in caudal process; striae clearly visible, running almost parallel to the body; several dicoidal chloroplasts; 4 to several rod-shaped paramylon grains. Specimens examined: BRAZIL: Minas Gerais: Pomba River, 16-VIII-2001, M.C.S. Soares s.n. (R205570). Distribution in Minas Gerais State: new record.

Phacus denisii Allorge \& Lefèvre, Bull. Soc. Bot. France 72:127. 1925.

Figures 11-12

Cells orbicular to broadly ovate, $21 \times 14 \mu \mathrm{m}$, with a prominent, bluntly-angled, dorsal keel reaching the posterior end of the cell; pellicle longitudinally striated; 1 discoid paramylun grain. Specimens examined: BRAZIL: MINAS GERAIS: Paraibuna River, 2-VII-2001, M.C.S. Soares s.n. (R205584).

Distribution in Minas Gerais State: new record.

Phacus longicauda (Ehrenb.) Dujard. var. tortus Lemmerm., Kryptogamenfl. Mark. Brandenburg 3:511. 1910.

Figure 13

Cells broadly ovate to ovate-elliptic, twisted, 63-76 x 21-37 $\mu \mathrm{m}$, posterior end gradually attenuated in caudal process, $18-28 \mu \mathrm{m}$; pellicle longitudinally striated; several chloroplasts, discoids; 1 discoid paramylun grain.

Specimens examined: BRAZIL: MinAS GERAIS: Paraibuna River, 2-VII-2001, M.C.S. Soares s.n. (R205584).

Distribution in Minas Gerais State: new record.

Trachelomonas armata (Ehrenb.) F. Stein var. armata, Infus. 3. 1878.

Figure 14

Lorica elliptical to ovoid, 33-34 x 28-29 $\mu$ m; wall reddishbrown, with several spines, 3-7 $\mu \mathrm{m}$.

Specimens examined: BRAZIL: MINAS GERAIS: Paraibuna River, 7-VII-2001, M.C.S. Soares s.n. (R205585).

Distribution in Minas Gerais State: Belo Horizonte (Giani et al. 1999, as Trachelomonas armata).

Trachelomonas recticollis (Playfair) Deflandre, Ehr. Rev. gen. Bot. 38:703. 1926.

Figure 57

Lorica spherical, 20-21 $\mu \mathrm{m}$, with cylindrical collar, $4 \mu \mathrm{m}$; wall smooth, reddish-brown. 

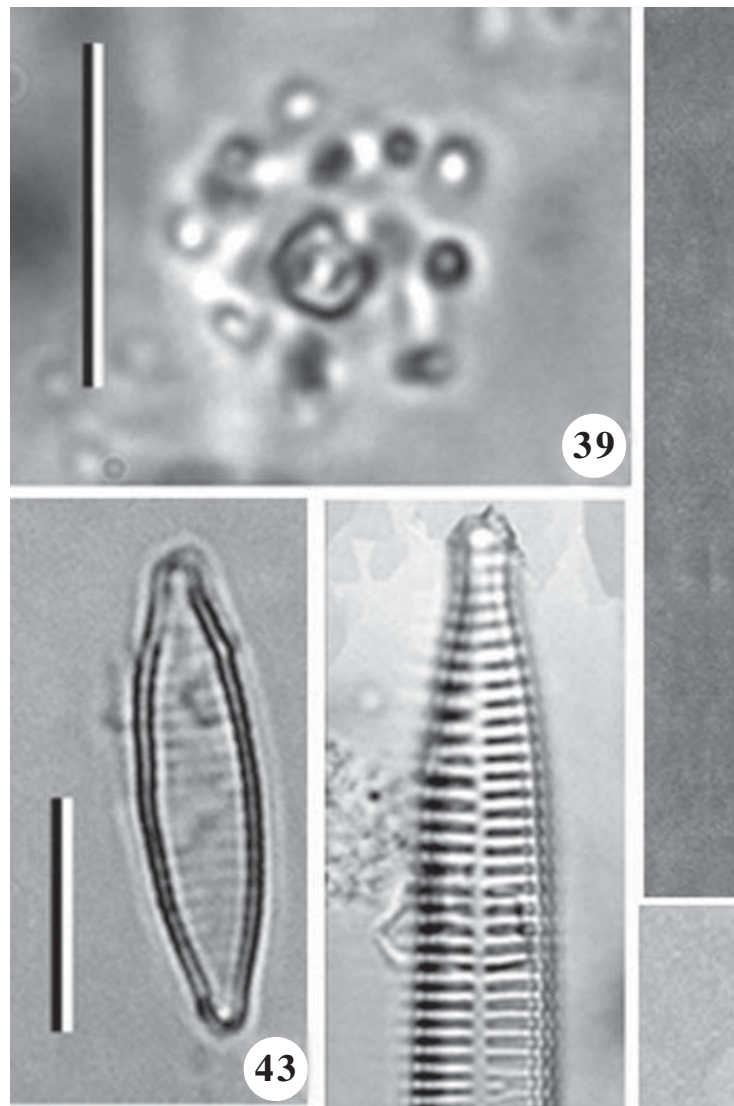

43
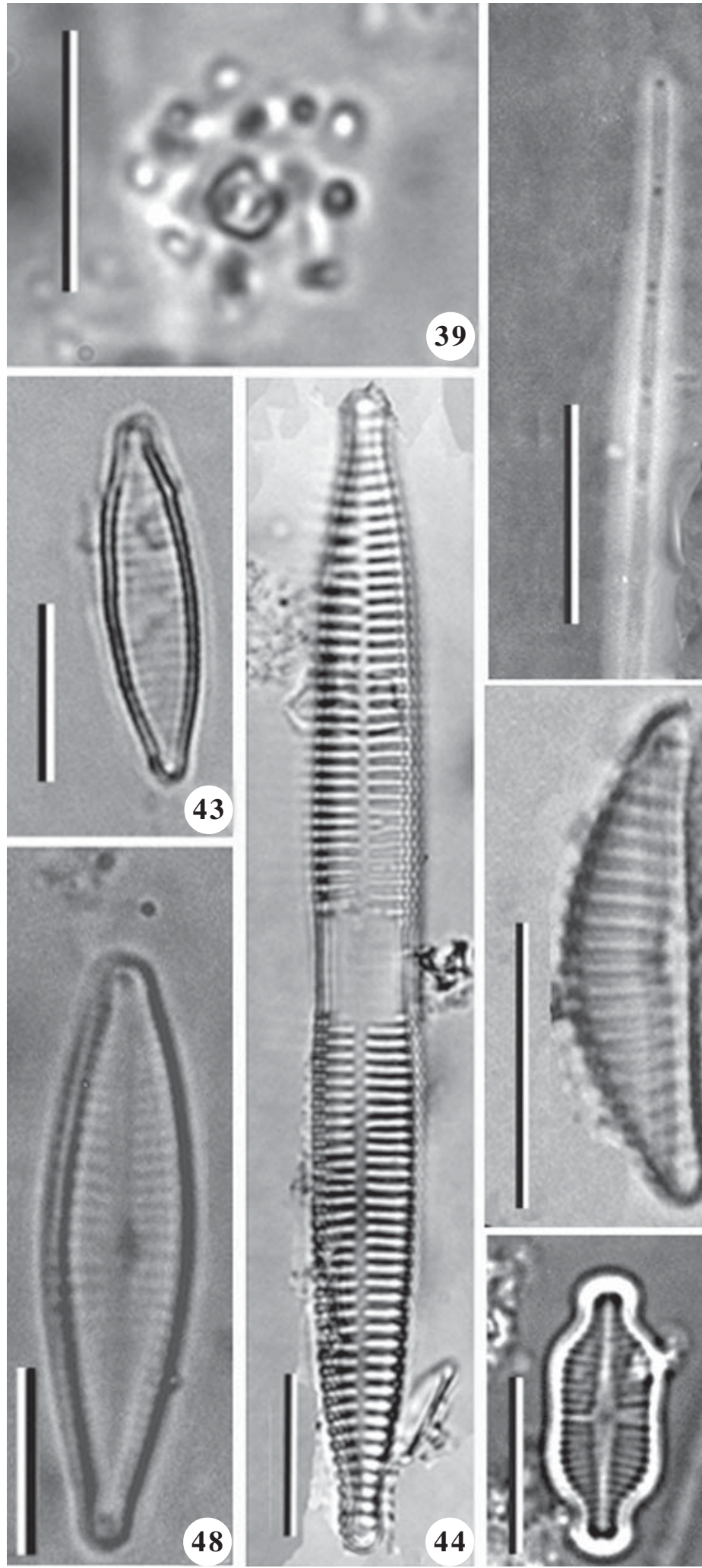
Specimens examined: BRAZIL: MinAs GERAIS: Paraibuna River, 2-VII-2001, M.C.S. Soares s.n. (R205585).

Distribution in Minas Gerais State: new record.

\section{CHLOROPHYCEAE}

\section{CHLOROCOCCALES}

\section{HYDRODICTYACEAE}

Hydrodyction reticulatum (L.) Lagerh., Öfvers. Förh. Kongl. Svenska Vetensk.-Akad. 40(2):71. 1883.

Figure 58

Cenobia macrosopic, saccate reticulum consisting of several cylindrical cells adjoined at their ends to form 5- or 6-side meshes, which are organized into a network; cells cylindrical 15-20 × $6 \mu \mathrm{m}$.

Specimens examined: BRAZIL: Minas Gerais: Pomba River, 16-VIII-2001, M.C.S. Soares s.n. (R205570).

Distribution in Minas Gerais State: new record.

Pediastrum tetras (Ehrenb.) Ralfs, Ann. Nat. Hist. 14: 469. 1844.

Figure 59

Cenobia rounded, 4-8 polygonal cells, outer margin with 2 bifurcate processes; cell $12 \times 7 \mu \mathrm{m}$.

Specimens examined: BRAZIL: MinAs GERAIS: Paraibuna River, 2-VII-2001, M.C.S. Soares s.n. (R205585).

Distribution in Minas Gerais State: Caldas, Lagoa Santa (Wille, 1884); Parque Nacional do Itatiaia (Bicudo \& Ventrice 1968); Viçosa (Lovo 1997).

\section{COELASTRACEAE}

Coelastrum pulchrum Schmidle var. pulchrum, Ber. Deutsch. Bot. Ges. 10:206. 1892.

Figure 60

Cenobia spherical, 8-16 cells; cells sub-ovate in lateral view, spherical in vertical view, 8-12 x 8-15 $\mu \mathrm{m}$, outer pole with conical-rounded projection; 5-6 interconnecting processes, uniting a neighboring cell.

Specimens examined: BRAZIL: MinAS GERAIS: Paraibuna River, 2-VII-2001, M.C.S. Soares s.n. (R205585, R205586). Distribution in Minas Gerais State: new record.

\section{ZYGNEMATOPHYCEAE}

\section{ZYGNEMATALES}

\section{MESOTAENIACEAE}

Spirotaenia condensata Bréb. in Ralfs, Brit. Desm. p.179. 1848.

Figure 15

Cells 6-10 times longer than broad, 173-193 x 17-28 $\mu \mathrm{m}$, cylindric, rounded apex; chloroplast a broad parietal band, making 10-12 close turns.
Specimens examined: BRAZIL: Minas GeRAIs: Pomba River, 16-VIII-2001, M.C.S. Soares s.n. (R205573).

Distribution in Minas Gerais State: new record.

\section{DESMIDIALES}

\section{CLOSTERIACEAE}

Closterium acutum (Lyngb.) Bréb. ex Ralfs var. acutum, Brit. Desm. p.177. 1848.

Figure 16

Cells 15 times longer than broad, 30-45 x 2-3 $\mu \mathrm{m}$, straight to moderately and uniformly curved; apex acutely rounded, $1 \mu \mathrm{m}$.

Specimens examined: BRAZIL: Minas GeraIs: Paraibuna River, 16-VIII-2001, M.C.S. Soares s.n. (R205585).

Distribution in Minas Gerais State: new record.

Closterium acutum var. linea (Perty) W. West \& G.S. West, Bot. Trans. Yorkshire Naturalists Union 5:57. 1900. Figure 17

Cells 16-25 times longer than broad, 50-100 x 3-4 $\mu \mathrm{m}$, mostly straighter and relatively longer than the typical, apex rounded, $2 \mu \mathrm{m}$.

Specimens examined: BRAZIL: Minas GeraIs: Paraibuna River, 16-VIII-2001, M.C.S. Soares s.n. (R205585).

Distribution in Minas Gerais State: new record.

Closterium acutum var. variabile (Lemmerm.) Krieg. in Rabenhorst, Kryptogamen-Flora 13(1/2):262. 1937. Figures 18-19

Cells thin 25-30 times longer than broad, 50-90 x 2-3 $\mu$ m, strongly curved, sometimes irregularly curved, apex rounded, $2 \mu \mathrm{m}$.

Specimens examined: BRAZIL: Minas Gerais: Paraibuna River, 2-VII-2001, M.C.S. Soares s.n. (R205585, R205587); 23-II-2002, M.C.S. Soares s.n. (R205596).

Distribution in Minas Gerais State: new record.

Closterium leibleinii Kütz. ex Ralfs var. leibleinii, Brit. Desm. 167. 1848.

Figure 20

Cells 7-9 times longer than broad, 125-136 x 15-18 $\mu \mathrm{m}$, strongly curved, ventral margin concave but tumid in median part; narrow, acutely rounded apex, 3-4 $\mu \mathrm{m}$; wall smooth. Specimens examined: BRAZIL: MinAs GERAIS: Pomba River, 16-VIII-2001, M.C.S. Soares s.n. (R205570). Distribution in Minas Gerais State: Lavras (Oliveira 2001).

Closterium navicula (Bréb.) Lütkem. var. navicula Cohn's Beitr. Biol. Pflanzen. 8:395. 1902.

Figure 21

Cell 3-4 times longer than broad, 67-78 x 14-24 $\mu$ m, broadly fusiform to ellipsoid; apices broadly rounded, 5-8 $\mu$; cell wall smooth. 
Specimens examined: BRAZIL: Minas Gerais: Pomba River, 16-VIII-2001, M.C.S. Soares s.n. (R205569, R205570).

Distribution in Minas Gerais State: new record.

\section{DESMIDIACEAE}

Cosmarium contractum Kirchn. var. minutissimum Grönblad, Commentat. Biol. 15(12): 26. 1956.

Figure 61

Cell 10-11 x $9 \mu \mathrm{m}$, isthmus 6-7 $\mu \mathrm{m}$, sinus very widely open; semicells elliptic.

Specimens examined: BRAZIL: MinAS GERAIS: Paraibuna River, 2-VII-2001, M.C.S. Soares s.n. (R205585).

Distribution in Minas Gerais State: new record.

Cosmarium formulosum Hoff var. formulosum, in Nordstedt, Vidensk. Meddel. Dansk. Naturhist. Foren. Kjöbenhavn. 194. 1888.

Figures 22-23

Cell 52-54 x 36-39 $\mu \mathrm{m}$, isthmus 8-10 $\mu \mathrm{m}$; semicells trapeziform-subsemicircular with a central tumor, sides evenly convex, 5-6 crenate; vertical view narrowly elliptic with a median tumor in both lateral margins.

Specimens examined: BRAZIL: Minas Gerais: Pomba River, 16-VIII-2001, M.C.S. Soares s.n. (R205570).

Distribution in Minas Gerais State: new record.

Cosmarium pseudoretusum Ducellier var. africanum (Fritsch) Krieg. \& Gerloff, Die Gattung Cosmarium 1.97. 1962.

Figures 24-25

Cell 30-33 x 25-28 $\mu \mathrm{m}$, isthmus 8-10 $\mu \mathrm{m}$; semicells in lateral view broadly elliptic, vertical view elliptic with a median tumor in both lateral margins.

Specimens examined: BRAZIL: Minas Gerais: Pomba River, 16-VIII-2001, M.C.S. Soares s.n. (R205569).

Distribution in Minas Gerais State: new record.

Cosmarium sphagnicolum W. West \& G.S. West var. sphagnicolum, J. Roy. Microscop. Soc. London. 1897: 486. 1897.

Figures 26-28

Cell 5-7 x 4-6 $\mu$ m, isthmus 3-4 $\mu \mathrm{m}$; semicells transversely oblong-rectangular; widely open sinus, 2-3 marginal papillas. Specimens examined: BRAZIL: MINAS GERAIS: Paraibuna River, 2-VII-2001, M.C.S. Soares s.n. (R205585, R205587, R205588, R205589, R205590, R205591, R205592); $23-$ II-2002, M.C.S. Soares s.n. (R205594, R205596, R205598, R205600, R205601).

Distribution in Minas Gerais State: new record.

This taxon showed a great morphological variation in the populational samples (figure 26-28). Prescot et al. (1981) showed on plate 258 , figure 3 , a very similar taxon, but identified as $C$. regnesi. The same author informs that the Brazilian $C$. regnesi taxon has reduced, rounded lateral margins, making the Brazilian species similar to C. sphagnicolum. Due to the great material variability in the samples, the taxon is still identified as Cosmarium sphagnicolum.

Cosmarium vexatum W. West var. vexatum, J. Roy. Microsc. Soc. London. 1892: 727. 1892.

Figure 29

Cells 41-44 x 36-39 $\mu \mathrm{m}$, at isthmus 11-13 $\mu \mathrm{m}$; median constriction deep; semicells pyramidal-truncate, lateral margins convex, undulate, apex truncate.

Specimens examined: BRAZIL: Minas Gerais: Pomba River, 16-VIII-2001, M.C.S. Soares s.n. (R205569).

Distribution in Minas Gerais State: new record.

Staurastrum leave Ralfs, Brit. Desm. 131. 1848.

Figures 30-31

Cells 15-18 x 12-14 $\mu \mathrm{m}$ (without processes) at isthmus 6-9 $\mu \mathrm{m}$, deeply constricted; semicell elliptic, apex and sides convex; each angle extended into a pair of process, slightly divergent, terminating in 2 teeth, one above the other; cell wall smooth.

Specimens examined: BRAZIL: Minas Gerais: Pomba River, 16-VIII-2001, M.C.S. Soares s.n. (R205569, R205570).

Distribution in Minas Gerais State: new record.

Staurastrum rotula Nordst., Vidensk. Meddel. Dansk. Naturhist. Foren. Kjöbenhavn. 227. 1869.

Figures 32, 62

Cells 32-35 x 51-54 $\mu \mathrm{m}$ (with processes) at isthmus 9$10 \mu \mathrm{m}$; median constriction deep semicell subhexagonal, 7 processes arising midway between apex and isthmus, long, horizontal or slightly divergent.

Specimens examined: BRAZIL: Minas GeRAIS: Paraibuna River, 16-VIII-2001, M.C.S. Soares s.n. (R205585).

Distribution in Minas Gerais State: Caldas (Nordstedt, 1870; 1877); Lagoa Santa (Wille 1884; Warming 1892); Lavras (Oliveira 2001).

Staurastrum tetracerum Ralfs, Ann. Mag. Nat. Hist. 15:150. 1845.

Figure 63

Cells 7-9 x 5-7 $\mu \mathrm{m}$ (without processes), 23-26 x 20-24 $\mu \mathrm{m}$ (with processes), isthmus 3-5 $\mu \mathrm{m}$, sinus narrow to open; semicell triangular, long processes, divergent; vertical view birradiate.

Specimens examined: BRAZIL: MINAS GERAIS: Paraibuna River, 2-VII-2001, M.C.S. Soares s.n. (R205585); 23-II2002, M.C.S. Soares s.n. (R205596, R205601). Distribution in Minas Gerais State: new record. 

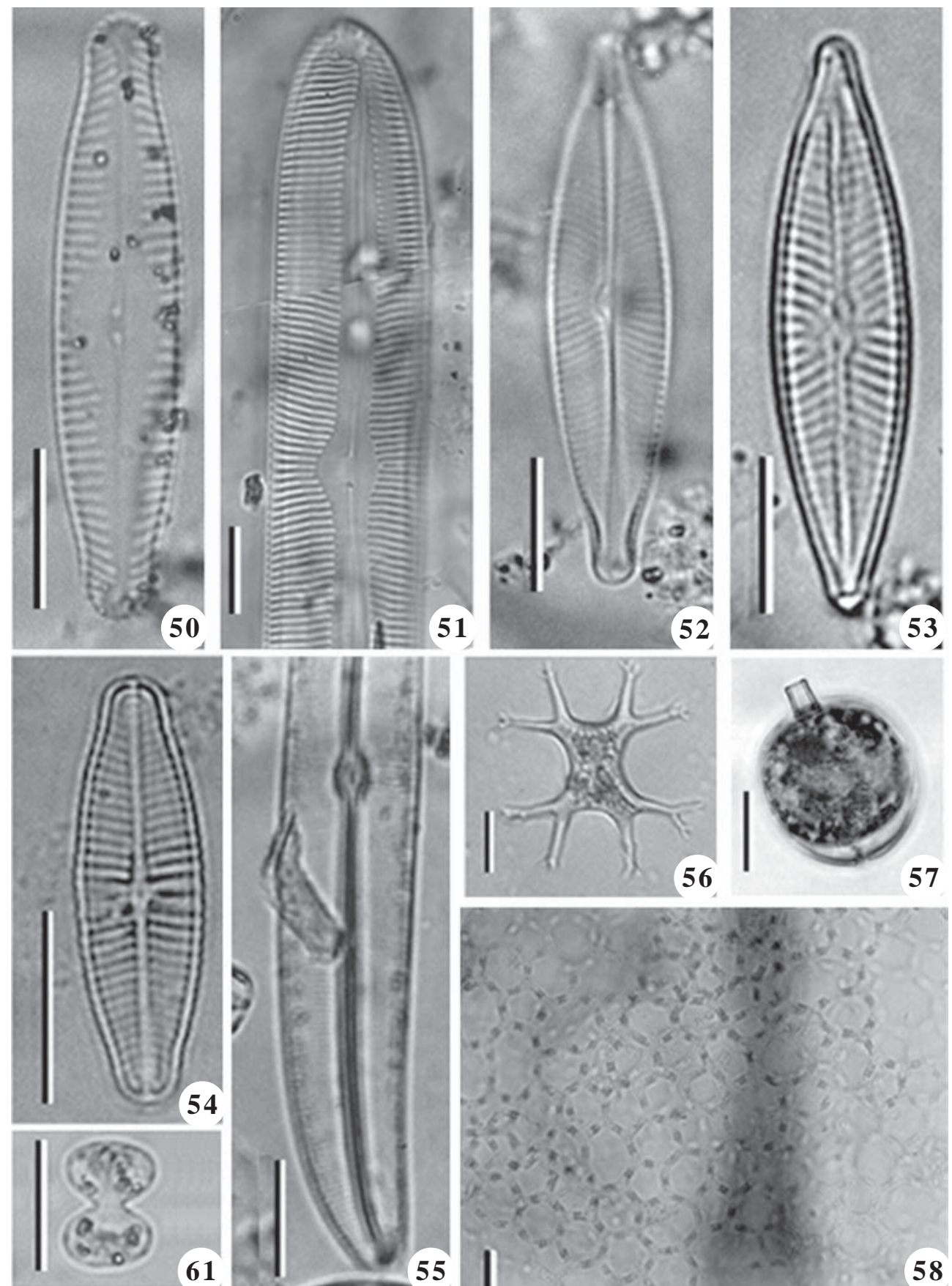

57
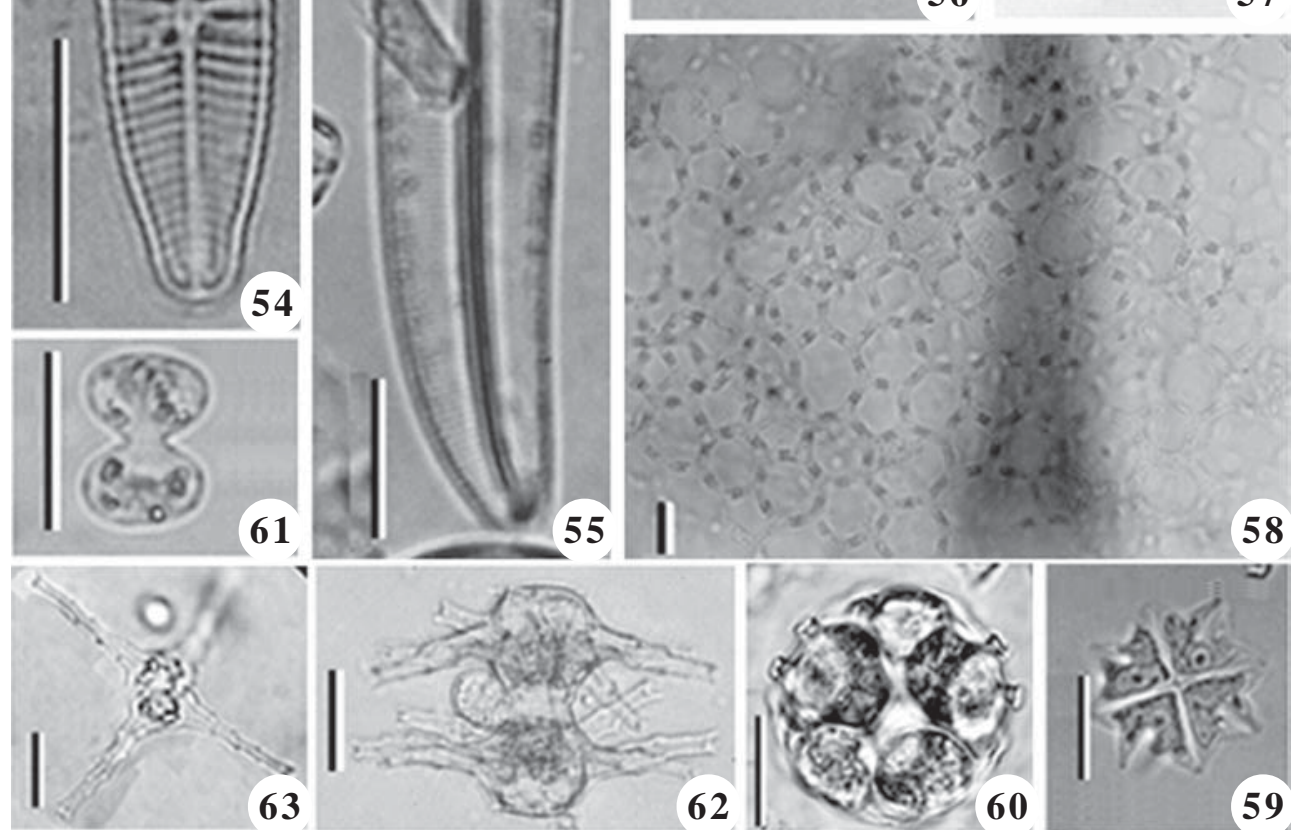

Figure 50-63. Bacillariophyceae, Xanthophyceae, Euglenophyceae, Chlorophyceae and Zygnematophyceae from Paraibuna and Pomba rivers. 50. Pinnularia microstauron. 51. P. viridis. 52. Navicula cryptocephala. 53. N. viridula var. rostellata. 54. Geissleria aikenensis. 55. Gyrosigma nodiferum. 56. Isthmochlorum gracile. 57. Trachelomonas reticollis. 58. Hydrodyction reticulatum. 59. Pediastrum tetras. 60. Coelastrum pulchrum var. pulchrum. 61. Cosmarium contractum var. minutissimum. 62. Staurastrum rotula, frontal view. 63. S. tetracerum, frontal view. Bars $=10 \mu \mathrm{m}$. 
Staurastrum trifidum Nordstedt var. inflexum W. West \& G.S. West, Trans. Linn. Soc. London, Bot. ser. 2, 5(5): 258. 1869.

Figures 33-34

Cells 25-28 x 22-25 $\mu \mathrm{m}$ (without processes), 35-38 $\mu \mathrm{m}$ (with processes), isthmus 11-13 $\mu \mathrm{m}$; median constriction deep; semicells subcuneate, apical margin truncate; spines at the apical angles sometimes recurved.

Specimens examined: BRAZIL: Minas Gerais: Pomba River, 2-VII-2001, M.C.S. Soares s.n. (R205570).

Distribution in Minas Gerais State: Caldas (Nordstedt 1870 , as $S$. trifidum).

Staurodesmus dejectus (Bréb. ex Ralfs) Teiling var. dejectus, Ark. Bot. 6(11):529. 1967.

Figures 35-36

Cells 17-20 x 14-16 $\mu \mathrm{m}$, isthmus 4-5 $\mu \mathrm{m}$; semicell cupshaped somewhat elongated, with short, divergent spines. Specimens examined: BRAZIL: Minas Gerais: Pomba River, 16-VIII-2001, M.C.S. Soares s.n. (R205571). Distribution in Minas Gerais State: Parque Nacional do Itatiaia (Bicudo \& Ventrice 1968); Lavras (Oliveira 2001 as $S$. dejectus).

Staurodesmus mamillatus (Nordst.) Teiling, Ark. Bot. 6(11):531. 1967.

Figures 37-38

Cells 18-30 x 25-35 $\mu \mathrm{m}$, isthmus 3-5 $\mu \mathrm{m}$; semicell triangular, apex margin convex, angles inflated, each cell with 1 long spine, parallel, triangular in apical view.

Specimens examined: BRAZIL: Minas Gerais: Pomba River, 16-VIII-2001, M.C.S. Soares s.n. (R205569, R205570).

Distribution in Minas Gerais State: new record.

Acknowledgments - The authors would like to thank Dra. Thelma Ludwig, "Universidade Federal do Paraná", MSc. Catharina Alves de Souza, "Museu Nacional", "Universidade Federal do Rio de Janeiro", for helping with diatoms and cyanobacteria identification, respectivelly.

\section{References}

ANAGNOSTIDIS, K. \& KOMÁREK, J. 1988. Modern approach to the classification system of cyanophytes: 3 - Oscillatoriales. Algological Studies 50-53:327-472.

BICUDO, C.E.M. 1969. Contribution to the knowledge of desmids of the state of São Paulo, Brazil (including a few from the state of Minas Gerais). Nova Hedwigia 17:433-549.

BICUDO, C.E.M. \& VENTRICE, M.R. 1968. Algas do Brejo da Lapa, Parque Nacional do Itatiaia, Brasil. In Anais do XIX Congresso da Sociedade Brasileira de Botânica., Fortaleza, p.1-30.
BICUDO, C.E.M., BICUDO, D.C., CASTRO, A.A.J. \& PICELLIVICENTIM, M. 1992. Fitoplâncton do trecho médio a represar do Rio Paranapanema (Usina Hidrelétrica de Rosana), Estado de São Paulo, Brasil. Revista Brasileira de Biologia 52:293-310.

BICUDO, D.C., BICUDO, C.E.M.,CASTRO, A.A.J. \& PICELLIVICENTIM, M.M. 1993. Diatomaceae (Bacillariophyceae) do trecho a represar do Rio Paranapanema (Usina Hidrelétrica de Rosana), Estado de São Paulo, Brasil. Hoehnea 20:47-68.

BITTENCOURT-OLIVEIRA, M.C. 2002. A comunidade fitoplanctônica do rio Tibagi: uma abordagem preliminar de sua diversidade. In A bacia do Rio Tibagi (M.E. Medri, E. Bianchini, O.A. Shibatta \& J.A. Pimenta, eds.). Londrina, M.E. Medri, p. 373-402.

BRANCO, C.C.Z. \& NECCHI JÚNIOR, O. 1996. Survey of stream macroalgae of eastern atlantic rainforest of São Paulo state, southeastern Brazil. Algological Studies 80: 35-57.

BRANCO, L.H.Z. \& NECCHI JÚNIOR, O. 1998. Distribution of macroalgae in three tropical drainage basis of southeastern Brazil. Archiv für Hydrobiologie 142:241-256.

BRANCO, L.H.Z., NECCHI JÚNIOR, O. \& BRANCO, C.C.Z. 1999. Cyanophyceae from lotic ecosystems of São Paulo, southeastern Brazil. Algological Studies 94:63-87.

BRASSAC, N.M. \& LUDWIG, T.A.V. 2003. Fragilariaceae (Bacillariophyceae) de rios da bacia do Iguaçu, Estado do Paraná, Brasil. Revista Brasileira de Botânica 26:311318.

BRASSAC, N.M. \& LUDWIG, T.A.V. 2005. Amphipleura e Diploneidaceae (Bacillariophyceae) da bacia do rio Iguaçu, PR, Brasil. Acta Botanica Brasilica 19:359-368.

BRASSAC, N.M., ATAB, D.R., LANDUCCI, M., VISINONI, N.D. \& LUDWIG, T.V. 1999. Diatomáceas cêntricas de rios na região de abrangência da usina hidrelétrica de Salto Caxias, PR (Bacia do Iguaçu). Acta Botanica Brasilica 13:227-289.

BUSELATO, T.C. \& AGUIAR, L.W. 1979. Diatomáceaes do Rio Ampituba, Torres, Rio Grande do Sul, Brasil. Iheringia, série Botânica 24:91-123.

CALLEGARO, V.L.M., SILVA, K.R.L. \& SALAMONI,E.S. 1993. Flórula diatomológica de ambientes lênticos e lóticos do Parque Florestal Estadual do Turvo, Rio Grande do Sul. Brasil. Iheringia, série Botânica 43:89-134.

CANANI, L.G.C. 2005. Flora e distribuição das diatomáceas (Bacillariophyta) epilíticas do Rio do Salto, Parque Estadual do Ibitipoca, Minas Gerais. Dissertação de mestrado, Universidade Federal do Rio de Janeiro, Rio de Janeiro.

CONTIN, L.F. 1990. Contribuição ao estudo das diatomáceas (Chrysophyta, Bacillariophyceae) na região de captação de água do Rio Iguaçu (SANEPAR), em Curitiba, Estado do Paraná, Brasil. Estudos em Biologia 24:1-95.

CÔRTE-REAL, M. \& AGUIAR, L.M. 1972. Diatomáceas do Arroio Dilúvio com referência às espécies de interesse sanitário e poluição. Iheringia, série Botânica 16:15-54. 
COSTA, J.C. \& TORGAN, L.C. 1991. Análise taxonômica de diatomáceas (Bacillariophyceae) do lago da Universidade Federal de Juiz de Fora, Minas Gerais, Brasil. Iheringia, série Botânica 41: 47-81.

DICKIE, G. 1881. Notes on the algae from the Amazons and its tributaries. Journal of the Linnean Society, Botany 18:123-132.

ETEROVICK, P.C. \& GIANI, A. 1997. Levantamento taxonômico das Chlorophyta (Volvocales, Chlorococcales, Zygnematales) do Reservatório da Pampulha, MG. Revista Brasileira de Botânica 20:79-90.

ETTL, H. 1978. Xanthophyceae. 1. In Süßwasserflora von Mitteleuropa 3(H. Ettl, J. Gerloff, H. Heynig \& D. Mollenhauer, eds.). Gustav Fisher, Ulm.

ETTL, H. 1983. Chlorophyta, I. Phytomonadina. In Süßwasserflora von Mitteleuropa 9 (H. Ettl, J. Gerloff, H. Heynig \& D. Mollenhauer, eds.). Gustav Fisher, Ulm.

FÖRSTER, K. 1963. Desmidiaceen aus Brasilien. 1: Nord-Brasilien. Revue Algologique, nouvelle série 7:38-92.

FÖRSTER, K. 1964. Desmidiaceen aus Brasilien. 2: Bahia, Goyaz, Piauhy und Nord-Brasilien. Hydrobiologia 23: 321-505.

FÖRSTER, K. 1969. Amazonische Desmidiaceen, 1: Areal Santarém. Amazoniana 2:5-231.

GIANI, A., FIGUEIREDO, C.C. \& ETEROVICK, P.C. 1999. Algas planctônicas do Reservatório da Pampulha (MG): Euglenophyta, Chrysophyta, Pyrrophyta, Cyanobacteria. Revista Brasileira de Botânica 22:107-116.

KLAVENESS, D. 1985. Classical and modern criteria for determining species of Cryptophyceae. Bulletin of Plankton Society of Japan 32:111-123.

KOMÁREK, J. \& ANAGNOSTIDIS, K. 1989. Modern approach to the classfication system of cyanophytes: 4 - Nostocales. Algological Studies 56:247-345

KOMÁREK, J. \& ANAGNOSTIDIS, K. 1999. Cyanoprokariota. 1. Chroococcales. In Süßwasserflora von Mitteleuropa 19(1) (H. Ett, G. Gärdner, H. Heynig \& D. Mollenhauer, eds.). Gustav Fisher, Ulm.

KOMÁREK, J. \& FOTT, B. 1983. Chlorophyceae (Grünalgen). Chlorococcales. In Das phytoplankton des süssawassers: systematic und biologie, 7(1) (G. Huber-Pestalozzi, ed.). E. Scweizerbart'sche Verlagsbuchlandlung, Stuttgart.

LANDUCCI, M. \& LUDWIG, T.A.V. 2005. Diatomáceas de rios da bacia hidrográfica litorânea, PR, Brasil: Coscinodiscophyceae e Fragilariophyceae. Acta Botanica Brasilica 19:345-357.

LAUDARES-SILVA, R. 1987. Estudo taxonômico das diatomáceas (Bacillariophyceae) coletadas no Arroio do Faxinal (Sanga de Água Boa), Torres, Rio Grande do Sul. Insula 17:3-184.

LOBO, E. \& TORGAN, L.C. 1988. Análise da estrutura da comunidade de diatomáceas (Bacillariophyceae) em duas estações do sistema Guaíba, Rio Grande do Sul, Brasil. Acta Botanica Brasilica, suplemento 1:103-119.
LOBO, E.A., CALLEGARO, V.L.M. \& OLIVEIRA, M.A. 1996. Pollution tolerant diatom from lotic systems in the Jacuí Basin, Rio Grande do Sul, Brazil. Iheringia, série Botânica 47:45-72.

LOVO, I.C. 1997. Flora de Clorofíceas (Divisão Chlorophyta) de um corpo d'água no campus da Universidade Federal de Viçosa, MG, Brasil. Tese de doutorado, Universidade Federal de Viçosa, Viçosa.

LUDWIG, T.A.V. \& FLÔRES, T. 1995. Diatomoflórula dos rios da região a ser inundada para a construção da Usina Hidrelétrica de Segredo, Paraná; I. Coscinodiscaceae, Bacillariophyceae (Achnanthales e Eunotiales) e Fragilariophyceae (Meridion e Asterionella). Arquivos de Biologia e Tecnologia 38:631-650.

LUDWIG, T.A.V. \& FLÔRES, T. 1997. Diatomoflórula dos rios da região a ser inundada para a construção da Usina Hidrelétrica de Segredo, Paraná; Fragilariophyceae (Fragilaria e Synedra). Hoehnea 24:55-65.

MARTAU, L., AGUIAR, L.W. \& CALLEGARO, V.L.M. 1977. Diatomáceas do Rio dos Sinos, Rio Grande do Sul, Brasil. Iheringia, Série Botânica 22:45-83.

NECCHI JÚNIOR, O. \& MOREIRA, J.C.L. 1995. Longitudinal distribution of macroalgae in two tropical lotic ecosystem from south-eastern Brazil. Archiv für Hydrobiologie 135:113-128.

NECCHI, JÚNIOR, O. \& PASCOALOTO, D. 1993. Seasonal dynamics of macroalgae communities in the Preto river basin, São Paulo, southeastern Brazil. Archiv für Hydrobiologie 129:231-252.

NECCHI JÚNIOR, O., PASCOALOTO, D. \& BRANCO, L.H.Z. 1994. Distribution of macroalgae in a tropical river basin from southeastern Brazil. Archiv für Hydrobiologie 129:459-471.

NECCHI JÚNIOR, O., BRANCO, C.C.Z. \& BRANCO, L.H.Z. 2000. Distribution of stream macroalgae in São Paulo State, southeastern Brazil. Algological Studies 97:43-57.

NORDSTEDT, C.F.O. 1870. Desmidiaceae. In: Symbolae ad floram Brasiliae centralis cognoscendam (E. Warming, ed). Videnskabelige Meddelelser fra den naturhistoriske Forening 1969:195-234.

NORDSTEDT, C.F.O. 1877. Nonnullae algae aquae dulcis brasiliensis. Öfvers K. Vetenskakad 34:15-28.

NORDSTEDT, C.F.O. 1878. Nonnullae algae aquae dulcis brasiliensis. Hedwigia 17:77-79.

OLIVEIRA, L. de. 2001. Desmidioflórula das represas Zootecnia e Estação da Universidade Federal de Lavras, Minas Gerais, Brasil: aspectos ecológicos e taxonomia. Dissertação de mestrado, Universidade Federal de Lavras, Lavras.

PRESCOT, G.W, CROSDALE, H.T. \& VINYARD, W.C. 1981. A synopsis of north american Desmids. Part II. Desmidiaceae: Placodermae section 3. University of Nebraska Press, Nebraska.

REYNOLDS, C.S. \& DESCY, J.P. 1996. The production, biomass and structure of phytoplankton in large rivers. Archiv für Hydrobiologie 113:161-187. 
REYNOLDS, C.S., DESCY, J.P. \& PADISÁK, J. 1994. Are phytoplankton dynamic in rivers so different from those in shallow lakes? Hydrobiologia 285:1-7

RODRIGUES, L. 1982. Contribuição ao conhecimento das diatomáceas do Rio Tubarão, Santa Catarina, Brasil. Insula 14:47-120.

RODRIGUES, L. 1992. Diatomoflórula do Rio Tubarão, Estado de Santa Catarina, Brasil: II: Naviculaceae Kützing. Insula 21:3-42.

RODRIGUES, L. \& MOREIRA FILHO, H. 1990. Diatomoflórula do Rio Tubarão, Santa Catarina, Brasil: I - Eunotiaceae Kützing e Achnanthaceae Kützing. Insula 20:113-135.

ROJO, C., COBELAS, M.A. \& ARAUZO, M. 1994. An elementary structure analysis of the river phytoplakton. Hydrobiologia 285: 43-55.

ROUND, F.E., CRAWFORD, R.M. \& MANN, D.G. 1990. The diatoms. Biology and morphology of genera. Cambridge University Press, Cambridge.

RUZICKA, J. 1977. Die Desmidiaceen Mitteleuropas. Band 1, 1 Lieferung. E. Schweizerbart'sche Verlagsbuchhandlung, Stuttgart.

RUZICKA, J. 1981. Die Desmidiaceen Mitteleuropas. Band 1, 1 Lieferung. E. Schweizerbart'sche Verlagsbuchhandlung, Stuttgart.

SCOTT, A.M., GRÖNBLAD, R. \& CROSDALE, H.T. 1965. Desmids from the Amazon Basin, Brazil, collected by Dr. H. Sioli. Acta Botanica Fennica 69:3-93.

SORMUS, L. 1991. Desmidiaceae (Zygnemaphyceae) da Serra do Cipó, Estado de Minas Gerais, Brasil. 1: Gênero Micrasterias C. Agardh ex Ralfs. Hoehnea 18:1-29.

SORMUS, L. 1993. Peniaceae (Zygnemaphyceae) da Serra do Cipó, Estado de Minas Gerais, Brasil. Hoehnea 20:69-77.
SORMUS, L. 1996. Desmidiaceae (Zygnemaphyceae) da Serra do Cipó, Estado de Minas Gerais, Brasil: Tribo Docidieae de Toni. Hoehnea 23:7-20.

TELL, G. \& CONFORTI, V. 1986. Euglenophyta pigmentadas de la Argentina. Bibliotheca Phycologica 75:1-301.

THOMASSON, K. 1971. Amazonian algae. Mémoires de l'Institute Royal dês Sciences Naturelles de Bélgique 86:1-57.

TORGAN, L.C. \& AGUIAR, L.W. 1978. Diatomáceas do "Rio" Guaíba, Porto Alegre, Rio Grande do Sul, Brasil. Iheringia 23:19-63.

TORRES, J.P.M. 1992. Ocorrência e distribuição de metais pesados no Rio Paraibuna, Juiz de Fora, M.G. Dissertação de mestrado, Universidade Federal do Rio de Janeiro, Rio de Janeiro.

VANDENHOEK, C., MANN, S.G. \& JAHNS, H.M. 1995. Algae: An Introduction to Phycology. Cambridge University Press, Cambridge.

VAN STOCH, H. A. 1970. Methodeu sur preparation kleider oder zarter kieseblemente für die elektronen und lichmikroskopie, insbesondere von diatomeen und bei geringen materialmenger. Zeitschrift fur wissenschaftliche Mikroskopie und mikroskopische Technik 70:29-32.

WARMING, E. 1892. Lagoa Santa. Et Bidrag til den biolo- giske Plantegeografi. Det Kongelige Danske Videnska- bemes Selskabs Skrifter 6:414-415.

WILLE, N. 1884. Bidrag til Syda merikas Algoflora, 1-3. Bihang till Kongliga Svenska Vetenskaps-akademiens handlingar 8:1-64.

ZÁKRYS, B. 1986. Contribution to the monography of Polish members of the genus Euglena Ehrenberg 1830. Nova Hedwigia 42:491-540. 